IZA DP No. 5394

Relational Contracts and the Economic Well-Being of Nations

Bohdan Kukharskyy

Michael Pflüger

December 2010 


\title{
Relational Contracts and the Economic Well-Being of Nations
}

\author{
Bohdan Kukharskyy \\ University of Passau \\ Michael Pflüger \\ University of Passau \\ DIW Berlin and IZA
}

\section{Discussion Paper No. 5394 \\ December 2010}

\author{
IZA \\ P.O. Box 7240 \\ 53072 Bonn \\ Germany \\ Phone: +49-228-3894-0 \\ Fax: +49-228-3894-180 \\ E-mail: iza@iza.org
}

\begin{abstract}
Any opinions expressed here are those of the author(s) and not those of IZA. Research published in this series may include views on policy, but the institute itself takes no institutional policy positions.

The Institute for the Study of Labor (IZA) in Bonn is a local and virtual international research center and a place of communication between science, politics and business. IZA is an independent nonprofit organization supported by Deutsche Post Foundation. The center is associated with the University of Bonn and offers a stimulating research environment through its international network, workshops and conferences, data service, project support, research visits and doctoral program. IZA engages in (i) original and internationally competitive research in all fields of labor economics, (ii) development of policy concepts, and (iii) dissemination of research results and concepts to the interested public.
\end{abstract}

IZA Discussion Papers often represent preliminary work and are circulated to encourage discussion. Citation of such a paper should account for its provisional character. A revised version may be available directly from the author. 
IZA Discussion Paper No. 5394

December 2010

\section{ABSTRACT}

\section{Relational Contracts and the Economic Well-Being of Nations ${ }^{*}$}

Informal long-term relationships and mutual confidence play a crucial role in modern economies in at least two dimensions. First, the performance of firms is strongly affected by their capacity to solve organizational questions effectively and this capacity is apparently strongly related to their ability to maintain informal long-term relationships. Second, countries that are better at maintaining unwritten agreements and where interactions are more strongly guided by a sense of trust fare better in terms of economic welfare than others. This paper provides a simple general equilibrium model which reconciles these two findings: we offer a micro-founded explanation of how the trust that prevails in an economy gets transmitted into higher economic well-being and we thereby highlight the role of managers with low time preference. Our analysis builds on the model of Antràs and Helpman (2004) and a formalization of the notion of relational contracting developed in Baker, Gibbons and Murphy (2002).

JEL Classification: D23, F14, L14, L22

Keywords: aggregate welfare, theory of the firm, relational contracting, firm heterogeneity

Corresponding author:

Michael Pflüger

Faculty of Economics

University of Passau

Innstrasse 27

94032 Passau

Germany

E-mail: michael.pflueger@uni-passau.de

\footnotetext{
Paper presented at seminars in Munich and Namur and at ETSG Lausanne. We thank Gani Aldashev, Christian Bauer, Mathias Hungerbuhler, Johann Lambsdorff, Jean-Philippe Platteau, Ludwig Ressner, Manuel Schubert, Monika Schnitzer and Eric Toulemonde for helpful comments.
} 


\section{Introduction}

Informal long-term relationships and mutual confidence play a crucial role in modern economies as is highlighted in two key findings. First, the performance of firms, as measured by indicators of productivity or profitability, is strongly related to their capacity to solve organizational questions effectively and this capacity, in turn, is apparently strongly related to their ability to engage in informal long-term relationships. Second, countries that are better at maintaining unwritten agreements and in which interactions are more strongly guided by a sense of trust fare better in terms of economic welfare than other countries.

This paper develops a simple general equilibrium model which reconciles these two observations. We build on the notion that a country's economic well-being is intimately connected to the performance of its firms since these transfer productive factors into final goods and services that serve the needs of its citizens. In our model, firms whose managers have low rates of time preference maintain efficient long-term relational contracts and, for this reason, perform better than firms which are run by more short-sighted agents. Furthermore, countries which are endowed with a higher share of long-term oriented managers exhibit higher social welfare.

Start with the first empirical finding. There is a large organizational literature which documents that firms exhibit astounding performance differences in terms of their productivity or profitability even after controlling for differences in conventionally measured inputs, technology and local market conditions (Bloom and Van Reenen 2010). Seemingly similar firms exhibit persistent performance differences as Beaulieu et al. (2010) have put it. ${ }^{1}$ How can these differences be explained? A solid body of empirical work documents that 'management matters': management practices differ widely in many dimensions and, hence, are key for an understanding of productivity differences across firms. Bloom and Van Reenen (2007, 2010), for example, offer an 18-item list of management practices that are associated with good firm performance. ${ }^{2}$ Of course, this finding raises a crucial follow-up question: why should it not be possible to simply

\footnotetext{
${ }^{1}$ The point comes out in impressive clarity in an intra-firm study by Chew et al. (1990). They looked at 40 operating units of a large firm that are highly similar in that all sites utilize the same technology, employ low-skilled labour, are located in the United States, serve fairly similar customers and produce fairly similar products. They found that the most productive units are twice as productive as the least productive ones, after accounting for a number of observable differences (e.g. age and size of plants, market size, labor markets, quality of output etc.). Similar findings have been corroborated in Argote et al. (1990), Henderson and Cockburn (1996), Ichniowski et al. (1997). See Beaulieu et al. (2010) for an extensive survey.

2 Their list comprises factors such as the introduction of modern manufacturing techniques, process problem documentation, performance tracking, review and dialogue, managing, retaining and attracting human capital,
} 
imitate and adopt the best-practice management techniques? Bloom and Van Reenen (2010) find that imperfectly competitive markets, family ownership of firms, restrictive regulations and informational barriers are conducive to bad management practices, whilst general education and multinational presence are favorable for good management practices. Without denying the importance of these factors, this hardly seems to be the full answer. A recent strand of research therefore emphasizes that possibly the main explanation for the perceived differences roots in an idea which was suggested by Stewart Macaulay (1963: 58) in a classic piece: "Businessmen often rely on 'a man's word' in a brief letter, a hand-shake, or 'common honesty and decency' - even when the transaction involves exposure to serious risks." In this view, superior practices are the fruit of such informal relational contracts which by their very nature are hard to detect from outside and even harder to imitate (Gibbons et al. 2010). ${ }^{3}$

The second finding that we have put forward above provides a strong further reason to focus on relational contracts: the economic well-being is higher in countries where informal relationships and trust play a stronger role. The idea that trustworthy relations are an important pillar for a society's economic success has a long tradition in the political and economic sciences. ${ }^{4}$ As Arrow (1972: 357) has put it: "Virtually every commercial transaction has within itself an element of trust, certainly any transaction conducted over a period of time. It can be plausibly argued that much of the economic backwardness in the world can be explained by the lack of mutual confidence [...]." In particular, a high correlation between countries' GDP per capita or its growth rate and different measures of trust and trustworthiness have been found in many studies. ${ }^{5}$ Clearly, causality could run eihter way, i.e. good economic perfomance could be the outcome of mutual confidence just as high levels of trust could be the result of higher levels of economic well-being. However, a recent analysis by Algan and Cahuc (2010) provides strong evidence that 'trust' is the cause of economic development, not the other way around. ${ }^{6}$

rewarding high performance and removing poor performers.

${ }^{3}$ A large literature shows that relational contracting is an important mechanism governing commercial transactions in developing and in developed countries. McMillan and Woodruff (1999) and Johnson et al. (2002) find relational contracting to be the main governance mechanism in Vietnam, Poland, Romania, Russia, Slovakia and the Ukraine. Even in countries with well-functioning legal systems courts are used mostly as a last resort in dispute settlement (Galanter 1981; Williamson 1983).

${ }^{4}$ See Arrow (1972), Gambetta (1988), Fukuyama (1995) and Putnam (1993).

${ }^{5}$ See, in particular, Knack and Keefer (1997), La Porta et al. (1997) and Dincer and Uslaner (2010).

${ }^{6} \mathrm{We}$ interpret the facts in the sense that the long-term orientiation and trustworthiness that prevails in business relationships is also reflected in higher measures of 'trust' on the aggregatet level as e.g. measured by the World Values Survey (WVS). We are aware that some studies which are based on experimental settings question the WVS measure of trust (e.g. Glaeser et al. 2000; Lazzarini et al. 2003). However, the result of these studies has been 
We reconcile these findings within a simple general equilibrium model with four key features which are pervasive in modern production and organization processes. First, we assume that the production process is fragmented in the sense that the final output is produced with two intermediate inputs, headquarter services (managers) and components. Second, firms, managed by headquarters, have to decide on the ownership structure, i.e. whether to integrate component suppliers (integration) or to acquire components through an arm's length transaction on markets (outsourcing). The choice between the two is dictated by hold-up problems that emerge when the intermediate inputs are relationship-specific, have no value outside the relationship and when contracts are incomplete as in the Property Rights Theory of the firm (Grossman and Hart 1986; Hart and Moore 1990). We build on Antràs and Helpman (2004) to capture these first two key features. Third, in order to allow long-term relationships to emerge, we embed this static framework into an infinitely repeated game similarly to Baker et al. (2002). This gives rise to two governance regimes: firms can either enter a relational agreement with the supplier once and forever (relational contracting) and thereby mitigate hold-up problems or they can negotiate in each period on the spot and thereby be stuck with hold-up problems as in the one-shot game (spot contracting). Overall, our analysis thus allows for four organizational modes, spot integration and outsourcing and relational integration and outsourcing. Fourth, we assume that firms are heterogeneous with respect to the time preference of their management ${ }^{7}$ and with respect to their productivity as in Melitz (2003). We would like to make it clear at the outset that none of our central findings crucially depends on the notion of firm heterogeneity with respect to technology. In fact, it will be seen that a firm's technology, while being an important characteristic, does not influence the organizational capabilities of the firms. To show this, we incorporate this type of heterogeneity in the model.

We obtain the following results. First and foremost, we show that long-term oriented managers are key for the superior performance of firms and the superior development of countries in terms of economic welfare. The reason for the superior performance of firms is that managers with low rate of time preference are able to maintain long-term relational contracts which mitigate (avoid)

challenged in more recent works (Fehr et al. 2003; Bellemare and Kroeger 2003). Furthermore, it may be questioned whether the concept of trust that emerges in experimental studies is really able capture the spirit of long-term relationships that prevail in business practice. See also Sapienza et al. (2008) on these issues.

7 Poterba and Summers (1995) provide anecdotic evidence for the differences in time horizons between CEO's. Several empirical studies provide evidence for heterogeneity of time preference rates on the individual level (e.g. Lawrance 1991, Samwick 1998, Warner and Pleeter 2001, Frederick et al. 2002). 
inefficiencies associated with hold-up problems in production. Removing such inefficiencies on the firm level transmits into higher aggregate welfare. Countries which have a larger share of managers with long-term orientation have higher welfare than countries where such managers are rare. Hence, we provide a micro-founded explanation of how the establishment of trustful mutual relations that is made possible by long-term oriented managers feeds into into higher economic well-being.

Second, we are able to show that in our full general equilibrium model the basic make-or-buy decision is similar under relational contracting as under spot contracting: if the headquarter intensity in production exceeds a well-defined threshold level, firms prefer relational integration to relational outsourcing whereas the opposite holds below this threshold.

Third, we derive a fundamental separation theorem: for any given productivity level, headquarters with low time preference are able to reap the fruits of relational contracts whereas those with high time preference are stuck with spot contracts. Hence, we obtain persistent performance differences between (technologically) similar firms in our general equilibrium model.

Fourth, our analysis endogenously explains the coexistence of organizational modes on the industry level - integration and outsourcing both in firms governed by spot contracting and by relational contracting.

Fifth, we show how the technology of firms interacts with their organizational capabilities in general equilibrium. Our model predicts that short-sighted firms need to be on average more technologically versed than more efficiently organized long-term oriented ones in order to be able to compete with the latter. This finding poses a challenge for empirical research. ${ }^{8}$

Related literature. Our paper relates to several strands of research. First, the concept of relational contracting that underlies our analysis has strong ties with the notion of 'trust' which is the subject of a substantive literature. One line of this literature uses the repeated game approach to formalize an economic concept of trust and trustworthiness (James Jr. 2002). Trust and

\footnotetext{
${ }^{8}$ Empirical work has so far addressed the link between the sorting pattern of organizational forms on the industry level and firms' productivities as predicted by Antràs and Helpman (2004). Nunn and Trefler (2008) and Kohler and Smolka (2009) find the particular sorting pattern predicted by Antràs and Helpman (2004) in the data. Defever and Toubal (2007) find the opposite sorting pattern, however. It should be noted that these studies use different kinds of total factor productivity as independent variable, thus, capturing the effects both of firm technology and better management practices on the organizational modes.
} 
relational contracts are used almost interchangeable in this approach, as exemplified by McLeods (2007: 609) characterization: "In a relational contract, one party trusts the other when the value from future trade is greater than the one period gain from defection." In accordance with this reasoning the model by Kvaloy and Olsen (2009) equates trust with the discount factor. In terms of our model this would amount to take the managers' rate of time preference as an expression of their level of trust or trustworthiness. Clearly, this would be a narrow notion of trust. In general, trust is seen as a multifaceted concept (see e.g. the contributions in Gambetta 1988).

Second, we build on the theoretical work in organizational economics that relates the organizational design of firms to their ability to enforce relation-based contracts (see the recent surveys by Hart 2002, MacLeod 2007 and Malcomson 2010). Specifically, we build on Baker et al. (2002) and Halonen (2002) in implementing a repeated game approach to overcome the holdup problem. ${ }^{9}$ In contrast to this literature, which uses partial equilibrium approaches to address single firms, our main concern are the aggregate consequences that emerge in general equilibrium, i.e. aggregate welfare and the sorting of firms in terms of their organizational strategies in general equilibrium.

Third, there is an emerging literature which addresses aggregate consequences of the organizational choices of firms with seminal works by Antràs (2003), and Antràs and Helpman (2004). ${ }^{10}$ We build on this work, as we already have made clear. This literature has not considered the notion of relational contracting, however. In fact, our contribution can be interpreted as introducing relational contracting in the form of a repeated game into this literature. Finally, there is an emerging literature which addresses the link between trust, relational contracts on the one hand and welfare and development on the other hand. Our analysis highlights the role of (long-term oriented) managers to explain how the trust that prevails in an economy is transmitted into higher economic well-being. ${ }^{11}$ Clearly, there are other transmission mechanisms as well. Guiso et al. (2004) show that trust has a positive effect on financial development. Moreover, trust also positively affects entrepreneurship (Guiso et al. 2006) and international trade and FDI flows (Guiso et al. 2009; Araujo and Ornelas 2007). ${ }^{12}$

\footnotetext{
${ }^{9}$ Felli et al. (2010) provide empirical evidence that higher levels of trust lead to higher supplier's investments in relationships between down- and up-stream firms.

${ }^{10}$ See also Antràs and Helpman (2008) and the surveys by Antràs and Rossi-Hansberg (2009) and Helpman (2006).

${ }^{11}$ See Dixit (2004) for a general theoretical treatment of the endogenous emergence of welfare enhancing institutions with social norms based on honesty or trust and the seminal empirical work by Greif $(1993,1994,2006)$.

12 There is also a related literature which studies the effect of different measures of institutional quality (e.g., legal
} 
The paper's structure is as follows. The basic model is laid out in section 2 . We start with the benchmark case of perfectly enforceable contracts and then we turn to spot contracting under contractual incompleteness. Section 3 characterizes the general equilibrium both for the benchmark case and for the case of contractual incompleteness. Section 4 introduces relational contracts and derives our main theorems. Section 5 briefly concludes.

\section{The model}

\subsection{General set-up}

We set up a tractable version of the model by Antràs and Helpman (2004) which integrates the Property Rights Theory of the firm by Grossman and Hart (1986) and Hart and Moore (1990) into the trade model of Melitz (2003). We consider a single closed economy populated by $L$ workers. Labor is the only factor of production and each worker supplies one unit. There are two industries, a traditional and a modern one. ${ }^{13}$ The traditional industry produces a homogeneous good under constant returns to scale and perfect competition. This good is the numéraire. The modern industry produces a continuum of differentiated varieties under monopolistic competition as in Dixit and Stiglitz (1977). Each variety is produced by a single firm under increasing returns to scale and firms are heterogeneous in their productivity as in Melitz (2003).

\subsection{Preferences and demand}

Preferences are given by a logarithmic quasi-linear utility function with CES sub-utility: ${ }^{14}$

$$
U=x_{0}+\mu \ln X \quad, \quad X=\left[\int_{i \in N} x(i)^{\alpha} \mathrm{d} i\right]^{1 / \alpha}
$$

where $x_{0}$ is consumption of the homogeneous good, $X$ denotes an index of aggregate consumption of differentiated varieties $x(i)$ and $N$ represents the mass of available varieties of the modern good (which will be determined endogeneously) and $\mu>0$ and $0<\alpha<1$ are parameters. The elasticity of substitution between any two varieties is given by $\sigma \equiv 1 /(1-\alpha)$.

Households maximize their utility given the budget constraint $P X+x_{0}=Y$, where a household's

enforcement of contracts) on the comparative advantage and the pattern of trade (Acemoglu et al. 2007, Costinot 2007, Levchenko 2007 and Nunn 2007).

${ }^{13}$ The model is easily extended to include many modern industries along the lines of Antràs and Helpman (2004), but the focus on two industries suffices for our purposes.

${ }^{14}$ We depart here from Antràs and Helpman (2004) in order to gain tractability. The logarithmic quasi-linear utility function is a special case of the more general quasi-linear upper tier utility function $U=x_{0}+\left(X^{\mu}\right) / \mu$ that they use. 
income is given by $Y$ and where the aggregate price index $P$ is defined by

$$
P \equiv\left[\int_{i \in N} p(i)^{1-\sigma} \mathrm{d} i\right]^{1 /(1-\sigma)},
$$

with $p(i)$ denoting the price of variety $i$. Standard utility maximization implies the demand functions $X=\mu P^{-1}$ and $x_{0}=Y-\mu$ for the manufacturing aggregate and the numéraire good, respectively. We assume that $\mu<Y$ in order to ensure positive consumption of the numéraire. Plugging the demand functions into (1) yields indirect utility $V=Y-\mu \ln P+\mu(\ln \mu-1)$.

Total demand for each variety $i$ is obtained by aggregating individual demands across the $L$ workers. This gives rise to the inverse demand function

$$
p(i)=\mu x(i)^{\alpha-1} X^{-\alpha} L^{1-\alpha} .
$$

Total revenue of each variety is then $R(i)=p(i) x(i)=\mu x(i)^{\alpha} X^{-\alpha} L^{1-\alpha}$. Note that the aggregate consumption index $X$ is exogenous from the viewpoint of a single producer but it is endogenous for the industry and will be determined in the industry equilibrium (see section 3).

\subsection{Technologies and entry}

Traditional good. The numéraire good is produced under constant returns to scale and perfect competition with a unit labor input requirement. This pins down the wage at unity in this economy.

Modern industry. The production of each variety $i$ of the differentiated modern good takes place under increasing returns to scale and it requires two customized relationship-specific inputs, headquarter services $h(i)$ supplied by headquarters $H$ and components $m(i)$ supplied by manufacturers $M .{ }^{15}$ These two intermediate inputs are themselves produced with one unit of labor per unit of output, each.

Before production can take place fixed investments (in terms of labor) of $f_{H}$ and $f_{M}$ have to be incurred by the headquarter and the component supplier, respectively. Departing from Antràs and Helpman (2004) we assume that these fixed investments are invariant with respect to the organizational options that we characterize below. ${ }^{16}$ The two variety-specific intermediate inputs

\footnotetext{
${ }^{15}$ Labor is the only factor of production here, so these agents can be understood as representing bundles of labor.

${ }^{16}$ Antràs and Helpman (2004) assume that these fixed costs are ownership-specific. They do so to obtain a coexistence of organizational forms in industry equilibrium. Arguably, this ad-hoc assumption sits uncomfortably with the idea of a 'unified theory of the firm' envisaged by Grossman and Hart (1986), however (cf. section 4.5). As will
} 
are then combined to produce variety $i$ of the final good according to the Cobb-Douglas production function

$$
x(i)=\theta(i)\left(\frac{h(i)}{\eta}\right)^{\eta}\left(\frac{m(i)}{1-\eta}\right)^{1-\eta}, \quad 0<\eta<1 .
$$

The parameter $\eta$ is industry-specific and represents the headquarter intensity in the production of variety $i$. The parameter $\theta(i)$ gives the firm-specific productivity similarly to Melitz (2003). We assume that firms are represented and run by the respective headquarters. Hence, $\theta(i)$ can be understood to be the ability of a headquarter firm to combine both inputs into a single final good. If the headquarter decides in favor of production, he seeks a component producer to cooperate with and decides about the organizational structure of the firm. This involves the choice between integration of the component supplier or outsourcing, i.e. an arm's length transaction on the market. The precise timing and the specifics of the organizational options will be specified fully below. Using (3) and (4) the joint revenue from cooperation of $H$ and $M$ is given by:

$$
R(i)=\mu(\theta(i))^{\alpha}\left(\frac{h(i)}{\eta}\right)^{\alpha \eta}\left(\frac{m(i)}{1-\eta}\right)^{\alpha(1-\eta)} X^{-\alpha} L^{1-\alpha} .
$$

The process of entry in this differentiated goods industry involves two steps as in Melitz (2003). Prior to entry, there is a large pool of potential firms (headquarters) who can enter the modern sector subject to an entry investment in terms of labor $f_{E}$ which is sunk thereafter. The firm $i$ then draws its productivity $\theta(i)$ from a commonly known distribution function $G(\theta)$. We call this the productivity lottery. Depending on this draw and the prevailing industrial structure a headquarter decides to immediately exit or to start production. To save on notation, we drop the variety index $i$ from now on.

\subsection{Investment decisions and profits under perfectly enforceable contracts}

The two inputs are relationship-specific and we assume that they have no value outside the specific relationship. If contracts are incomplete, these assumptions entail hold-up problems that we take up in section 2.5. In this section we address the benchmark case in which courts can perfectly verify and enforce contracts so that the investment decisions of the two parties are undistorted. Call this the first-best solution from the point of view of producers. ${ }^{17}$ This 
benchmark serves as a reference point in our analysis of spot contracts and it plays a crucial role in the analysis of relational contracts that we undertake in section 4.

With full contractibility, the contracting parties $H$ and $M$ can ex ante stipulate the levels of investments into headquarter services and manufacturing components, which maximize joint firm's profit $\pi(h, m)=R(h, m)-m-h-f$, where $f \equiv f_{M}+f_{H}$. Using (5), standard profit maximization yields the optimal investments (the agents are compensated with their marginal revenue product for their variable factor input)

$$
h^{*}=\eta \alpha A E L \Theta X^{-\frac{\alpha}{1-\alpha}} \quad, \quad m^{*}=(1-\eta) \alpha A E L \Theta X^{-\frac{\alpha}{1-\alpha}},
$$

where $A \equiv \alpha^{\frac{\alpha}{1-\alpha}}$ and $E \equiv \mu^{\frac{1}{1-\alpha}}$. The parameter $\Theta \equiv \theta^{\frac{\alpha}{1-\alpha}}$ is an alternative measure of productivity. Using (6) in (5) gives first-best revenue

$$
R^{*}=A E L \Theta X^{-\frac{\alpha}{1-\alpha}}
$$

Utilizing (4) and (6) in (3) yields the pricing rule for a firm with productivity $\theta$

$$
p^{*}(\theta)=\frac{1}{\theta} \frac{1}{\alpha},
$$

where $1 / \alpha>1$ is the monopoly mark-up over marginal costs $(1 / \theta)$. Joint pure profits in the firstbest case can then be obtained using (6) and (7):

$$
\pi^{*}(\theta, X)=(1-\alpha) A E L \Theta X^{-\frac{\alpha}{1-\alpha}}-f
$$

The distribution of profits is immaterial in this first-best case since the variable labor inputs of the agents are rewarded with their marginal revenue products which induces optimal investment and since their fixed investments $f \equiv f_{M}+f_{H}$ are compensated as expressed by (9).

If contracts are perfectly verified and enforced by courts, the organizational structure does not matter. Any allocation that can be implemented through a given organizational form could be implemented within any other ownership structure through the appropriate choice of a comprehensive contract. However, this is no more the case if contracts are incomplete.

\subsection{Contractual incompleteness}

\subsubsection{Assumptions}

Incomplete contracts. In practice, courts are unable to perfectly verify and enforce the quality of 
investments into headquarter services and manufacturing components. Since the investments of the two parties are assumed to be relationship-specific and have no value outside the relationship, hold-up problems emerge. We address these with the Property Rights Theory of the firm along the lines of Grossman and Hart (1986) and Hart and Moore (1990). Since courts will be incapable of solving potential disputes between contracting parties, the level of each party's investments is left out from the ex ante contract. Consequently, the agents play a non-cooperative game with respect to their ex ante investments, i.e. each agent chooses its own profit-maximizing investment, taking the investment of his production partner as given. The investment incentives of each party depend on the organizational form, i.e. whether both units are integrated or not. We assume that courts can verify and enforce the ex ante choice of the organizational structure.

Timing. The timing of the non-cooperative game that we consider is summarized in figure 1 . After $H$ bears the fixed entry cost $f_{E}$ and draws productivity $\theta$, he decides whether to leave the industry immediately or to stay and produce. Once he enters the market, he chooses in $t_{0}$ the organizational form, i.e. whether to integrate a component producer into the firm boundaries or to outsource manufacturing production to an independent supplier. Since the parties negotiate about all future contingencies on the spot in the game that we consider in this section, we call these two organizational options spot integration ( $S I$ ) and spot outsourcing ( $S O$ ). Each headquarter thus offers a contract which stipulates the organizational form $k \in\{S I, S O\}$.

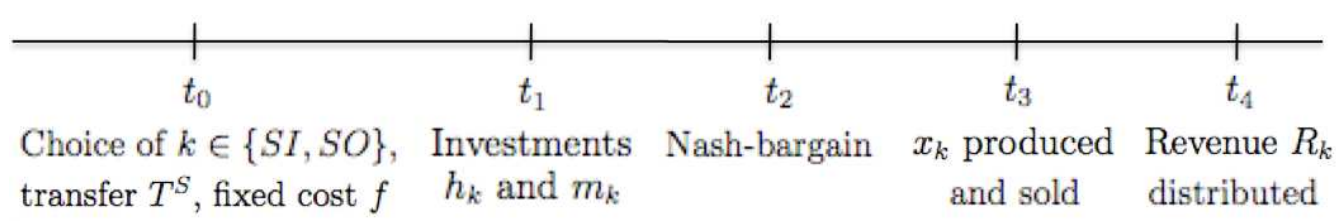

Figure 1: Timing of the non-cooperative game.

The ensuing analysis is simplified by assuming that in $t_{0}$ the headquarter also stipulates an upfront transfer $T^{S}$ that has to be paid by the component producer $M$ for participation in the relationship. In fact, combining this assumption with the further assumption that there is an infinitely elastic supply of component suppliers (whereas the number of headquarters $H$ is strictly finite), there will be a competitve bidding process among suppliers which secures the firm their participation at least cost as in Antràs and Helpman (2004). The result of this competitive bidding process is that the expected profit of $M$ from the relationship with the headquarter is driven to $M$ 's ex-ante outside option which we normalize to zero. 
Once the cooperation between $H$ and $M$ is founded, both parties simultaneously choose their investment levels $h_{k}$ and $m_{k}$ in $t_{1}$. When these specific investments are completed, their quantity is observable by both partners and by the courts.

In $t_{2}$, the parties get together to negotiate about the division of the surplus. In accordance with the Property Rights Theory of the firm, we assume that surplus sharing takes place according to generalized Nash-bargaining. Each party thus gets her outside option plus a share of the quasi rent (i.e. the revenue generated inside the relationship net of each party's outside option). Let $\beta_{k} \in(0,1)$ denote the headquarters' share that is stipulated at the negotiation stage $t_{2}$ under organizational mode $k=S I, S O$ (hence $1-\beta_{k}$ is the share that accrues to $M$ ). The revenue shares $\beta_{k}$ and $1-\beta_{k}$ depend both on the exogenous bargaining weights $\beta$ and $1-\beta$ of the headquarter and the supplier respectively as well as on the exogenous outside options that are available to the two parties under the two organizational forms. The revenue shares are thus also exogenous. Specifically, we follow Antràs and Helpman (2004) in imposing the following assumptions. Under spot outsourcing, $H$ owns input $h_{S O}$ and $M$ possesses the property rights for input $m_{S O}$. By assumption, both inputs are highly specific, so that their value outside the relationship is zero. Therefore, the Nash-bargaining delivers the headquarter an ex post payoff $0+\beta\left(R_{S O}-0-0\right)=\beta R_{S O}$ and the manufacturing producer an ex post payoff $(1-\beta) R_{S O} . H$ 's revenue share under spot outsourcing is thus determined solely by his bargaining power, i.e., $\beta_{S O}=\beta$. Under spot integration, $M$ is $H$ 's employee and therefore the headquarter possesses property rights for manufacturing inputs $m_{S I}$. While the outside option of the component supplier in this case is still zero, the outside option of the headquarter is now positive, as the latter can use both inputs in the production process. However, we assume that if the bargaining fails the finalgood producer can produce only a fraction $\delta \in(0,1)$ of the output that could be produced with the cooperation of the supplier. ${ }^{18}$ By substituting $(\delta x)$ for $x$ in the revenue function $R=\mu x^{\alpha} X^{-\alpha} L^{1-\alpha}$, we get the outside option of the headquarter in case of spot integration, $\delta^{\alpha} R_{S I}$. Hence, $H$ gets the payoff $\delta^{\alpha} R_{S I}+\beta\left(R_{S I}-\delta^{\alpha} R_{S I}-0\right)=\left[\beta+\delta^{\alpha}(1-\beta)\right] R_{S I}=\beta_{S I} R_{S I}$ and the

\footnotetext{
18 This assumption follows Antràs and Helpman (2004). It accords with the fact that, during production, the component supplier $M$ typically accumulates some idiosyncratic know-how, which the headquarter is unable to appropriate in case that the bargain fails.
} 
supplier obtains the payoff $\left(1-\beta_{S I}\right) R_{S I}$. To sum up, the headquarter obtains a larger share of the revenue under integration than under outsourcing

$$
\beta_{S I} \equiv \beta+\delta^{\alpha}(1-\beta)>\beta=\beta_{S O}
$$

In $t_{3}$, headquarter services and manufacturing components are (costlessly) combined to final output according to technology in (4) and the final goods are produced and sold. In $t_{4}$, the revenue is distributed according to the sharing rule that was agreed in the spot contract in $t_{2}$.

\subsubsection{Investment decisions and profits}

This one-shot game is solved through backward induction. To find a subgame perfect equilibrium, we first consider the investment decisions of both parties. In $t_{1}, H$ invests $h_{k}$ which maximizes $\beta_{k} R_{k}-h_{k}$, whereas $M$ provides $m_{k}$ that maximizes $\left(1-\beta_{k}\right) R_{k}-m_{k}$ where $R_{k}$ is the revenue that emerges under the organizational form $k \in\{S I, S O\}$. The first-order conditions of these maximization problems imply the best-response functions $h_{k}=\beta_{k} \alpha \eta R_{k}$ and $m_{k}=\left(1-\beta_{k}\right) \alpha(1-\eta) R_{k}$. Utilizing these in (5) yields revenue

$$
R_{k}=\beta_{k}^{\frac{\alpha \eta}{1-\alpha}}\left(1-\beta_{k}\right)^{\frac{\alpha(1-\eta)}{1-\alpha}} A E L \Theta X^{-\frac{\alpha}{1-\alpha}}
$$

which can then be used in the best-response functions to solve out for the investments:

$$
\begin{aligned}
& h_{k}=\beta_{k}^{\frac{1-\alpha(1-\eta)}{1-\alpha}}\left(1-\beta_{k}\right)^{\frac{\alpha(1-\eta)}{1-\alpha}} \eta \alpha A E L \Theta X^{-\frac{\alpha}{1-\alpha}} \\
& m_{k}=\beta_{k}^{\frac{\alpha \eta}{1-\alpha}}\left(1-\beta_{k}\right)^{\frac{1-\alpha \eta}{1-\alpha}}(1-\eta) \alpha A E L \Theta X^{-\frac{\alpha}{1-\alpha}} .
\end{aligned}
$$

It is apparent from comparing (7) and (11) that the revenue under incomplete contracs is smaller than in the first-best case. This reflects that $h_{k}<h^{*}$ and $m_{k}<m^{*}$ which immediately follows from comparing (6) and (12). Intuitively, in the absence of complete contracts each party anticipates ex post to be held up by its cooperation partner and, therefore, underinvests ex ante. This hold-up problem is also reflected in a higher price charged by a firm with productivity $\theta$ 


$$
p_{k}(\theta)=\frac{1}{\theta} \frac{1}{\alpha} \cdot \frac{1}{\left(\beta_{k}\right)^{\eta}\left(1-\beta_{k}\right)^{1-\eta}}
$$

where $1 /\left(\beta_{k}\right)^{\eta}\left(1-\beta_{k}\right)^{1-\eta}>1$ (for all $\left.\beta_{k}, \eta \in(0,1)\right)$ is the cost factor that arises due to contractual incompleteness. Using (11) and (12) we can derive the pure profit under spot contract $k$ as:

$$
\pi_{k}(\theta, X)=\Psi_{k} A E L \Theta X^{-\frac{\alpha}{1-\alpha}}-f,
$$

where

$$
\Psi_{k} \equiv \beta_{k}^{\frac{\alpha \eta}{1-\alpha}}\left(1-\beta_{k}\right)^{\frac{\alpha(1-\eta)}{1-\alpha}}\left(1-\alpha\left[\beta_{k} \eta+\left(1-\beta_{k}\right)(1-\eta)\right]\right)
$$

embraces all terms that include an organizational-specific index $k \in\{S I, S O\}$. Comparing (9) with (14) reveals that profits under spot contracting are lower than first-best profits, i.e. $\pi_{k}<\pi *$ iff $\Psi_{k}<(1-\alpha)$. This holds true indeed:

Lemma 1. It holds true for all permissible parameter values that $\Psi_{k}<(1-\alpha)$.

\section{Proof. See Appendix A.}

The ex ante transfer $T^{S}$ from $M$ to $H$ combined with the assumption that there is an infintitely elastic supply of component suppliers implies that the total surplus from the spot relationship accrues to the headquarter. A component supplier is left with zero net profits:

$$
\pi_{M k}=\beta_{k}^{\frac{\alpha \eta}{1-\alpha}}\left(1-\beta_{k}\right)^{\frac{1-\alpha \eta}{1-\alpha}}(1-\alpha(1-\eta)) A E L \Theta X^{-\frac{\alpha}{1-\alpha}}-f_{M}-T^{S}=0 .
$$

\subsubsection{Organizational choice}

Since $\pi_{M k}=0$, joint pure profits under either spot contract $k \in\{S I, S O\}$ accrue to the headquarter $H$, i.e. $\pi_{H k}=\pi_{k}$. Thus, the headquarter chooses ex ante the organizational form $k$ which maximizes joint pure profits given by (14) and (15) and it thereby also implicitly determines the ex post revenue share $\beta_{k}$. We call the resulting profits third-best $(T B):^{19}$

\footnotetext{
${ }^{19}$ We call these profits third-best from the point of view of producers to contrast this case with the hypothetical second-best case where the headquarter is freely able to choose the revenue share $\beta^{*} \in(0,1)$ during ex post bargaining: the headquarter would thus select $\beta^{*}$ such that it achieves the highest possible profits under contractual incompleteness. It is a defining element of the Property Rights Theory of the firm that it takes the revenue shares $\beta_{k} \in\left\{\beta_{S I}, \beta_{s o}\right\}$ as exogenous and distinct. The hypothetical second-best solution serves as a useful reference point to identify whether spot integration or spot outsourcing are more profitable as Antràs and Helpman (2004) have shown. We provide a discussion of the second-best case in appendix B.
} 


$$
\pi_{k}^{T B}=\max _{k \in\{S I, S O\}} \pi_{k}(\theta, X)
$$

Since fixed costs are identical in both ownership structures, the make-or-buy decision reduces to a comparison of the operating profits, $\Pi_{k}$. Let $\Pi_{s}(\eta)$ denote the ratio of operating profits under spot integration to those under spot outsourcing. Using (14) and (15), we have:

$$
\Pi_{S}(\eta) \equiv \frac{\Pi_{S I}}{\Pi_{S O}}=\frac{1-\alpha\left(\beta_{S I} \eta+\left(1-\beta_{S I}\right)(1-\eta)\right)}{1-\alpha\left(\beta_{S O} \eta+\left(1-\beta_{S O}\right)(1-\eta)\right)}\left(\left(\frac{\beta_{S I}}{\beta_{S O}}\right)^{\eta}\left(\frac{1-\beta_{S I}}{1-\beta_{S O}}\right)^{1-\eta}\right)^{\frac{\alpha}{1-\alpha}}
$$

The relative attractiveness of spot integration, as measured by $\Pi_{S}(\eta)$, can be shown to increase in the headquarter intensity of production (see appendix $\mathrm{C}$ and figure 2).

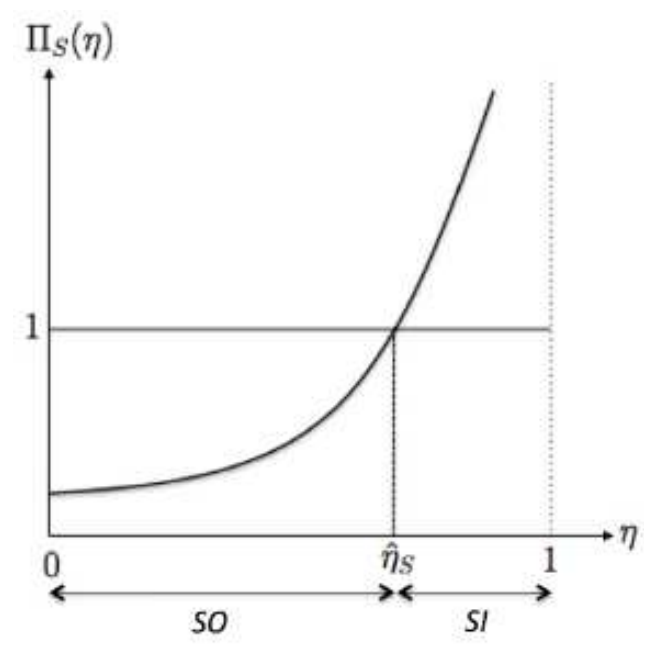

Figure 2: Organizational choice in the spot game.

Intuitively, the relative importance of investments in headquarter services rises in $\eta$. By integrating a supplier into the firm boundaries, the headquarter gets higher ex ante investment incentives. Moreover, it can be shown that there is a unique critical threshold $\hat{\eta}_{S} \in(0,1)$ at which spot integration becomes more profitable than spot outsourcing. Hence, we have:

Proposition 1. Organizational choice under spot contracting. There exists a unique headquarter intensity $\hat{\eta}_{s} \in(0,1)$ such that if $\eta<\hat{\eta}_{S}$ all firms will outsource manufacturing production, whereas if $\eta>\hat{\eta}_{S}$ all firms will integrate the suppliers. In industry with a headquarter intensity $\hat{\eta}_{S}$ firms are indifferent between the two organizational forms.

Proof. See Appendix C. 


\section{General equilibrium in the spot game}

\subsection{Equilibrium conditions and parameterization}

Having characterized the choices of firms after the productivity is drawn both in the benchmark case with complete contracts and under contractual incompleteness, we now move to the equilibrium in the modern sector. As in Melitz (2003), this equilibrium can be characterized by two conditions, a zero cutoff profit condition and a free entry condition.

It should be noted at the outset that the general equilibrium of the economy follows immediately once the industry equilibrium in the modern sector is derived, as is well-known from the twosector models of the new trade theory (cf. Helpman and Krugman 1985) of which the present model is a variant. Equilibrium in the modern sector defines the resource use (labor use) of that sector. The remaining labor is used to produce the outside good. By Walras law it follows that the expenses on the aggregate consumption of the outside good and the modern good just match the wage income generated in this economy.

All the results derived so far hold for any productivity distribution $G(\theta)$. However, both to accord with empirical findings and in order to obtain closed-form solutions we assume from now on that productivities $\theta$ are drawn from a Pareto distribution with lower bound $b$ and shape parameter $z:^{20}$

$$
G(\theta)=1-\left(\frac{b}{\theta}\right)^{z}, \quad \theta \geq b>0, \quad b, z=\text { const }, \quad g(\theta)=\frac{d G(\theta)}{d \theta}=z b^{z} \theta^{-z-1}
$$

where $g(\theta)$ is the corresponding probability density function. We impose the assumptions $z>2$ to ensure that the Pareto-distributed variable has a well-defined (finite) variance and the further assumption $z>\sigma-1$ to obtain economically meaningful solutions (see appendix D).

\subsection{Equilibrium under perfectly enforceable contracts}

This section derives the equilibrium for the benchmark case of perfectly enforceable contracts. After paying the fixed entry costs $f_{E}$ and drawing its productivity $\theta$, the headquarter decides whether to exit immediately or to start producing. It will start producing if the profits from doing so are non-negative. The zero cutoff profit condition (ZCPC*) defines the cutoff productivtity $\theta^{*}$

\footnotetext{
20 The Pareto distribution has been extensively used in the literature on heterogeneous firms, see, e.g. Kortum (1997), Helpman et al. (2004, 2008) and Melitz and Ottaviano (2008).
} 
which solves $\pi^{*}(\theta, X)=0$, i.e. the (endogenous) threshold level, from which on firms are active:

$(\mathrm{ZCPC} *)$

$$
\theta^{*}(X)=X\left[\frac{f}{(1-\alpha) A E L}\right]^{\frac{1-\alpha}{\alpha}}
$$

Headquarters will incur the fixed entry costs $f_{E}$ to participate in the productivity lottery, if the expected pure profits are at least equal to $f_{E}$. The free entry condition (FEC*) commands:

$\left(\mathrm{FEC}^{*}\right)$

$$
\int_{\theta^{*}}^{\infty} \pi^{*}(\theta, X) d G(\theta)=f_{E}
$$

where $\pi^{*}$ and $\theta^{*}$ are given by (9) and (20), respectively. We show in appendix D that (21) can be solved for the aggregate consumption index $X^{*}$ in the first-best case and that $\theta^{*}$ is then immediately implied by (20):

$$
X^{*}=b\left(\frac{f}{f_{E}} \frac{\sigma-1}{(z-\sigma+1)}\right)^{\frac{1}{z}} \cdot\left(\frac{(1-\alpha) A E L}{f}\right)^{\frac{1-\alpha}{\alpha}} \Rightarrow \theta^{*}=b\left(\frac{f}{f_{E}} \frac{\sigma-1}{(z-\sigma+1)}\right)^{\frac{1}{z}}
$$

All other endogenous variables are then easily obtained. The average productivity of active firms, $\tilde{\theta}^{*}$, is proportional to the cutoff productivity, $\tilde{\theta}^{*}=[z /(z-\sigma+1)] \frac{1}{\sigma-1} \theta^{*}>\theta^{*}$ as we show in appendix D. The price level follows from using $X^{*}$ in $P=\mu X^{-1}$. This gives us: $P^{*}=\left(\theta^{*} \alpha\right)^{-1}[(1-\alpha) \mu L / f]^{-\frac{1-\alpha}{\alpha}}$. Following Melitz (2003), the CES price index can be rewritten in terms of the average productivity, $P^{*}=N^{\frac{1}{1-\sigma}} \cdot p\left(\tilde{\theta}^{*}\right)=N^{-\frac{1-\alpha}{\alpha}} \cdot\left(1 / \alpha \tilde{\theta}^{*}\right)$. Using $P^{*}$ this can be solved out for the mass of manufacturing firms (varieties) in the market, $N^{*}=[z-\sigma+1 /(f z)] \mu L(1-\alpha)$. We complete the characterization of equilibrium in this benchmark case with an expression for welfare:

$$
V^{*}=1-\mu \ln P^{*}+\mu(\ln \mu-1)
$$

where the price level $P^{*}$ is as characterized before.

\subsection{Equilibrium under contractual incompleteness}

The equilibrium under contractual incompleteness can be derived by analogy to the previous 
section. The zero cutoff profit condition in this third-best case $\left(\mathrm{ZCPC}^{T B}\right)$ requires $\pi_{k}^{T B}(\theta, X)=0$ and implies the cutoff productivity under spot contracting:

$\left(\mathrm{ZCPC}^{T B}\right)$

$$
\theta^{T B}(X)=X\left(\frac{f}{\Psi_{k} A E L}\right)^{\frac{1-\alpha}{\alpha}}
$$

All firms with productivities exceeding this threshold start to produce. Comparing (20) and (24) reveals that, for any given level of aggregate consumption say $\bar{X}, \theta^{T B}(\bar{X})>\theta^{*}(\bar{X})$ as long as $\Psi_{k}<(1-\alpha)$, which holds true according to Lemma 1. Hence, under contractual incompleteness a higher productivity is needed in order to start producing. The free entry condition under contractual incompleteness $\left(\mathrm{FEC}^{T B}\right)$ requires:

$$
\left(\mathrm{FEC}^{T B}\right) \quad \int_{\theta^{T B}}^{\infty} \pi_{k}^{T B}(\theta, X) d G(\theta)=f_{E},
$$

where $\pi_{k}^{T B}$ and $\theta^{T B}$ are given by (17) and (24), respectively. Following the approach sketched in appendix D this condition can be solved for the aggregate consumption index and for the cutoff productivity:

$$
X_{k}^{T B}=b\left(\frac{f}{f_{E}} \frac{\sigma-1}{(z-\sigma+1)}\right)^{\frac{1}{z}} \cdot\left(\frac{\Psi_{k} A E L}{f}\right)^{\frac{1-\alpha}{\alpha}} \Rightarrow \theta^{T B}=b\left(\frac{f}{f_{E}} \frac{\sigma-1}{(z-\sigma+1)}\right)^{\frac{1}{z}} .
$$

Two important insights merit to be mentioned here. First, Lemma 1 implies that the aggregate consumption index under contractual incompleteness is lower than in the benchmark. Second, the cutoff productivity in the third-best case equals the threshold productivity in the first-best case and, hence, is not influenced by contractual incompleteness. Consequently, the average productivity is the same as well, $\tilde{\theta}^{T B}=\tilde{\theta}^{*}$. Nevertheless, due to the additional cost factor associated with incomplete contracting (see eq. (13)), the average price of the monopolistic producers, $p_{k}^{T B}\left(\tilde{\theta}^{T B}\right)=\frac{1}{\tilde{\theta}^{T B}} \frac{1}{\alpha} \cdot \frac{1}{\left(\beta_{k}\right)^{\eta}\left(1-\beta_{k}\right)^{1-\eta}}$, is higher as compared to the benchmark. This gets also reflected in a higher CES price index, $P_{k}^{T B}=\left(\theta^{T B} \alpha\right)^{-1}\left[\Psi_{k} \mu L / f\right]^{-\frac{1-\alpha}{\alpha}}>P^{*}$, and a higher mass of firms, $\quad N_{k}^{T B}=\left[P_{k}^{T B} / p_{k}^{T B}(\tilde{\theta})\right]^{\frac{\alpha}{1-\alpha}}=[(z-\sigma+1) /(f z)] \mu L \cdot \gamma_{k}>N^{*} \quad$ (where $\left.\gamma_{k} \equiv 1-\alpha\left[\beta_{k} \eta+\left(1-\beta_{k}\right)(1-\eta)\right]>1-\alpha\right)$. The higher price level immediately entails that welfare

$$
V_{k}^{T B}=1-\mu \ln P_{k}^{T B}+\mu(\ln \mu-1),
$$


is lower compared to the benchmark case with complete contracts. We have thus proven:

Proposition 2. Comparision of equilibria. Comparing the equilibrium with incomplete contracts with the equilibrium under perfectly enforceable contracts yields: $X_{k}^{T B}<X^{*}$, $\theta^{T B}=\theta^{*}, p_{k}^{T B}>p^{*}$ and $P_{k}^{T B}>P^{*}$. Welfare is lower under incomplete contracts, $V_{k}^{T B}<V^{*}$.

\section{$4 \quad$ Relational contracting}

\subsection{Assumptions}

Set-up. Business cooperations involving relationship-specific investments are the ones where we would expect long-term relationships to prevail. We now embed the one-shot game of section 2.5 into a repeated game with infinitely lived agents. We build on Baker et al. (2002) and assume that firms can either enter a relational agreement once and forever or negotiate in each period of the repeated game on the spot. This section introduces our assumptions concerning the relational game. In the subsequent sections we analyze the tradeoff between spot and relational contracting.

Short- and long-term orientation. We assume heterogeneity of firms with respect to time preference $r \in[\varepsilon, 1]$ where $\varepsilon$ is an arbitrary small positive number. ${ }^{21}$ To simplify the notation, we omit the firm-index $i$ right away. Headquarters with high $r$ strongly discount future profits and, hence, are more short-term oriented than headquarters with small $r$. In analogy to the productivity lottery (cf. section 2.3) where firms draw $\theta$ from $G(\theta)$, we assume that the rates of time preference $r$ are drawn from an ex ante known distribution function $\Gamma(r)$, after the fixed cost of entry are payed. For simplicity it is assumed that these two draws are independent.

Timing. The timing of the repeated game is as follows (see figure 3). Upon paying the fixed cost of entry, the firm headquarter draws his productivity $\theta$ and time preference $r$ which then prevail in perpetuity. He then decides whether to leave the industry immediately or to start production which involves per-period fixed production costs $f=f_{M}+f_{H}$. In the latter case, the headquarter seeks a supplier to cooperate with in perpetuity, i.e. in $t=0, \ldots, \infty$. Each period $t$ consists of subperiods $t_{0}, \ldots, t_{4}$ in which the successive stages needed to produce the final good take place. Headquarters that start production make two decisions in subperiod $t_{0}$. First, they decide whether to integrate a component supplier or to source out component production. In either case, both

\footnotetext{
${ }^{21}$ We exclude the case $r=0$ that implicates infinitely long-term oriented firms.
} 
parties stipulate the ownership structure in the ex ante (explicit) contract. Second, headquarters decide whether to play the spot game infinitely $(S)$ or to engage in relational contracting $(R)$. In the former case, the upper path of figure 3 applies which indicates that the stages in the subperiods are as in the one-shot game (cf. figure 1). In the latter case the headquarter offers a relational obligation to undertake first-best efficient investment (cf. the lower path in figure 3). In order to distinguish this game from the spot game described in section 2.5 , we define the organizational modes under relational contracting as $\kappa=R I, R O$, i.e. relational integration and relational outsourcing, respectively. ${ }^{22}$ In the case of relational contracting we impose a specific informational environment and we assume that a transfer-bonus system applies whose rationale we explain in the next paragraph. The component supplier pays the per-period upfront transfer $T^{R}$ in order to participate in the relational cooperation in $t_{0}$. In $t_{1}$ the headquarter commits to pay a bonus $B$ in $t_{4}$ to the supplier if the latter provides first-best efficient investments. If both parties stick to the relational agreement, the first-best investments $\left(h^{*}, m^{*}\right)$ as specified in (6) are made in $t_{2}$, the first-best output $\left(x^{*}\right)$ is produced and sold in $t_{3}$ and the headquater pays a part $B$ of the first-best revenue $R^{*}$ to the supplier in $t_{4}$. If both parties honor the contract in period $t=0$, the implicit agreement described above will prevail for the rest of the game (i.e., in $t=1, \ldots, \infty)$. The headquarter's choice of the governance mode (spot vs. relational) is analyzed in section 4.5.

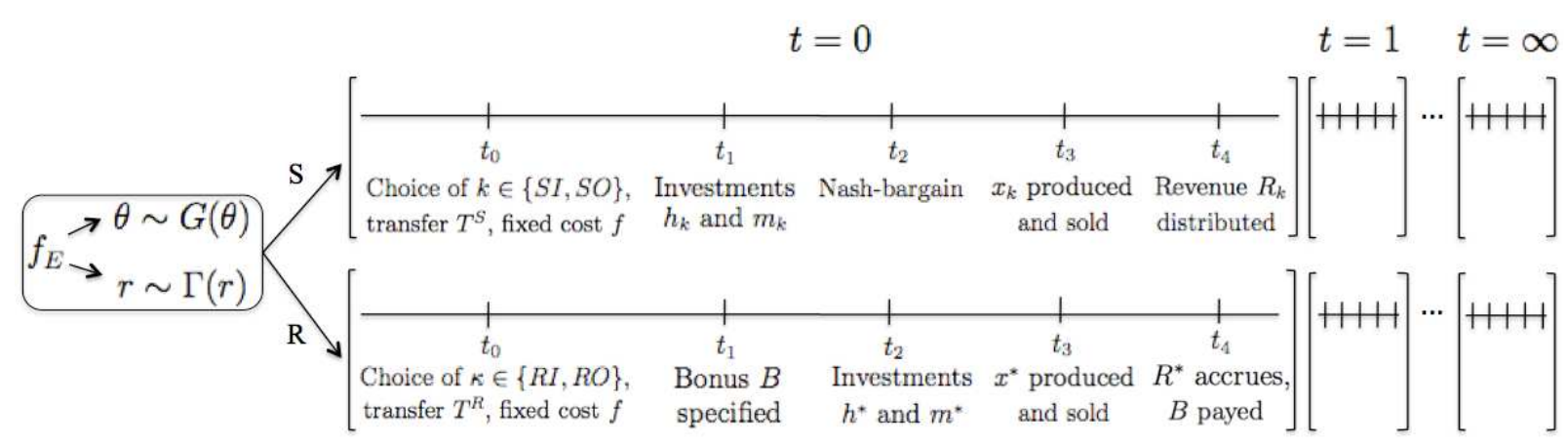

Figure 3: Timing in the repeated game.

Informational environment, upfront transfer and ex post bonus. To gain simplicity in the one-shot game of section 2 we have employed the idea of an up-front transfer $T^{S}$ and the

\footnotetext{
${ }^{22}$ As these agreements are implicitly made, there is no difference between a spot and a relational contract from a legal perspective. Put differently, if the contracting parties stipulate, for instance, outsourcing as ownership structure, the courts cannot verify whether the cooperation proceeds via the spot or the relational governance regime.
} 
assumption of an infinitely elastic supply of component-suppliers. A competitive bidding process ensured that the $M$ 's were driven to their outside option and that all joint pure (spot) profits accrued to the headquarters. We maintain these assumptions for the upper path of figure 3 which portrays spot contracting. In order to gain similar simplicity under relational contracting, we impose the following assumptions in the repeated game. We assume that, after the productivity and the rate of time preference are drawn by the headquarters $H$, both become common knowledge to the component suppliers $M .^{23}$ Under relational contracting, headquarters offer a relational obligation in which they implicitely commit to undertake first-best efficient investment. Component suppliers applying for these cooperations similarly implicitly promise to provide their optimal investment. However, as both parties' investments are made simultanously and implicit commitments can not be verified by the courts, the $M$ 's are always tempted to underinvest ex ante and, by holding up the cooperative party, thus to obtain one-shot deviation profits ex post. To rule out that such deviation is profitable for suppliers and in order to gain the simplicity of the oneshot game, we assume that an upfront transfer $T^{R}$ needs to be paid by the suppliers in order to participate in the relational cooperation $(R)$. Since the pool of potential suppliers is strictly larger than the mass of headquarters, the former will overbid each other with respect to this upfront payment $T^{R}$ until $M$ 's ex post deviation profits are driven to their ex-ante outside option (normalized to zero). Bearing in mind that the $M$ 's are tempted to renege once the relational cooperation has been established, $H$ implicitely commits to pay ex post a bonus $B$ to $M$, if the latter does not renege (i.e., provides the first-best investment). This bonus pays back the upfront payment and compensates $M$ 's fixed and variable effort at his opportunity cost $(w=1){ }^{24}$

Trigger strategies. The relational contract is implicit, so each party may renege on it. More specifically, $M$ defects $(D)$ on the implicit agreement by providing a suboptimal investment level $m_{\kappa}^{D}<m^{*}$, while $H$ behaves cooperatively (i.e., invests $h^{*}$ ). Analogously, $H$ can cheat the cooperative party $M$ (that invests $m^{*}$ ) by delivering $h_{\kappa}^{D}<h^{*}$ and then refusing to pay the

\footnotetext{
${ }^{23}$ The assumption that the time preference rate $r$ is perfectly observable by component suppliers, as strong as it might appear, is not very restrictive, in fact. Alternatively, one could assume that the $M$ 's do not know the idiosyncratic time preference rates of the $H$ 's but that they possess knowledge about the distribution of $r$ 's in the economy. Utilizing this assumption makes the model more cumbersome to solve without altering the main results.

${ }^{24}$ The payment of the bonus is also in the best interest of headquarters: if they do not pay out the bonus after the supplier has provided the first-best investment, the cooperation is destroyed for all future periods. However, it is easy to show that if headquarters were ever tempted not to live up to their promises, they would do so by cheating in the investment. Hence, if from the point of view of headquarters a relational contract exists which dominates an infinite succession of spot contracts, then paying the bonus is in the best interest of headquarters to maintain the relational
} 
promised bonus $B$. If either party deviates from the implicit agreement, the relational contract is broken and the resulting surplus in this period is shared via generalized Nash-bargaining. For simplicity, we assume that, for a given ownership structure, parties' bargaining shares in this period correspond to those under spot contracting (i.e, $\beta_{R I}=\beta_{S I}$ and $\beta_{R O}=\beta_{S O}$ ). ${ }^{25}$ Once a relational agreement is broken, the party who did not renege refuses to enter into a new relational contract with the opportunistic party. Furthermore, we assume that neither of the existing partners can enter into a new relational agreement with some third party. ${ }^{26}$ Therefore, the two parties live forever under spot governance (as specified in section 2.5) in case of a failure of a relational agreement. Following Baker et al. (2002), we allow the headquarters to choose anew the ownership form in the spot contract prevailing in all subsequent periods $t=1, \ldots, \infty$.

Table 1 illustrates the per period pure profits and the respective investments of both parties under the trigger strategies desribed above. $\pi_{H \kappa}^{D \mid H}$ denotes the payoff of party $H$ (lower index) under organizational form $\kappa=R I, R O$ if this party (upper index) defected upon the relational agreement. The defection payoff of party $M$ is defined analogously. Both parties' one-shot deviation profits are derived in the folowing section.

\begin{tabular}{|c|c|c|c|c|}
\hline$H$ & $t=0$ & $t=1$ & $t=2$ & $\ldots$ \\
\hline Cooperate & $\pi_{H}^{*}\left(h^{*}, m^{*}\right)$ & $\frac{\pi_{H}^{*}}{1+r}$ & $\frac{\pi_{H}^{*}}{(1+r)^{2}}$ & $\ldots \quad \pi_{H}^{*}+\sum_{t=1}^{\infty}\left(\frac{1}{1+r}\right)^{t} \pi_{H}^{*}=\pi_{H}^{*}+\frac{\pi_{H}^{*}}{r}$ \\
\hline Defect $(D)$ & $\pi_{H \kappa}^{D \mid H}\left(h_{\kappa}^{D}, m^{*}\right)$ & $\frac{\pi_{H k}^{T B}\left(h_{k}, m_{k}\right)}{1+r}$ & $\frac{\pi_{H k}^{T B}}{(1+r)^{2}}$ & $\ldots \quad \pi_{H \kappa}^{D \mid H}+\sum_{t=1}^{\infty}\left(\frac{1}{1+r}\right)^{t} \pi_{H k}^{T B}=\pi_{H \kappa}^{D \mid H}+\frac{\pi_{H k}^{T B}}{r}$ \\
\hline$M$ & $t=0$ & $t=1$ & $t=2$ & $\infty$ \\
\hline Cooperate & $\pi_{M}^{*}\left(h^{*}, m^{*}\right)$ & $\frac{\pi_{M}^{*}}{1+r}$ & $\frac{\pi_{M}^{*}}{(1+r)^{2}}$ & $\ldots \quad \pi_{M}^{*}+\sum_{t=1}^{\infty}\left(\frac{1}{1+r}\right)^{t} \pi_{M}^{*}=\pi_{M}^{*}+\frac{\pi_{M}^{*}}{r}$ \\
\hline Defect $(D)$ & $\pi_{M \kappa}^{D \mid M}\left(h^{*}, m_{\kappa}^{D}\right)$ & $\frac{\pi_{M k}^{T B}\left(h_{k}, m_{k}\right)}{1+r}$ & $\frac{\pi_{M k}^{T B}}{(1+r)^{2}}$ & $\ldots \quad \pi_{M \kappa}^{D \mid M}+\sum_{t=1}^{\infty}\left(\frac{1}{1+r}\right)^{t} \pi_{M k}^{T B}=\pi_{M \kappa}^{D \mid M}+\frac{\pi_{M k}^{T B}}{r}$ \\
\hline
\end{tabular}

Table 1: Trigger strategy in the repeated game.

contract. We analyze this incentive compatibility constraint below.

${ }^{25}$ The analysis can be just as well conducted under the assumptions $\beta_{R I} \neq \beta_{S I}$ and $\beta_{R O} \neq \beta_{S O}$.

${ }^{26}$ This can be motivated by the assumption that all existing cooperations are registered in a Commercial Registry, which is common knowledge for all market participants. However, neither the terms of the relational contract nor the identity of the reneging party can be detected by a third person. By assuming that a party who was cheated upon in the relational contract cannot credibly signalize her cooperative behavior to third parties, no third party will have an incentive to enter into a new relational agreement with a party who just contracted out. 


\subsection{Profits on the deviation path}

Consider first the case where $M$ defects on the relational contract whilst $H$ provides the firstbest investment $h^{*}$. This breaks the contract and leads to a division of the surplus in this period (say $t=0$ ) according to generalized Nash-bargaining. $M$ 's program is then to $\max _{m_{\kappa}^{D}}\left(1-\beta_{\kappa}\right) R\left(h^{*}, m_{\kappa}^{D}\right)-m_{\kappa}^{D}-f_{M}-T^{R}$ s.t. $h^{*}=\eta \alpha A E L \Theta X^{-\frac{\alpha}{1-\alpha}}$ which implies the following one-shot investment and revenue on the deviation path:

$$
m_{\kappa}^{D}=\left(1-\beta_{\kappa}\right)^{\frac{1}{1-\alpha(1-\eta)}}(1-\eta) \alpha A E L \Theta X^{-\frac{\alpha}{1-\alpha}} \Rightarrow R\left(h^{*}, m_{\kappa}^{D}\right)=\left(1-\beta_{\kappa}\right)^{\frac{\alpha(1-\eta)}{1-\alpha(1-\eta)}} A E L \Theta X^{-\frac{\alpha}{1-\alpha}}
$$

Comparing (6), (12) and (28) it is apparent that $m_{k}<m_{\kappa}^{D}<m^{*}$ for all $\alpha, \eta, \beta_{k}=\beta_{\kappa} \in(0,1)$. On the deviation path $M$ underinvests in period 0 relative to the first-best case, but still invests more than in the third-best case. ${ }^{27}$ Hence, we have the following gradation of revenues: $R_{k}\left(h_{k}, m_{k}\right)<R_{\kappa}\left(h^{*}, m_{\kappa}^{D}\right)<R\left(h^{*}, m^{*}\right) . M$ 's pure profit in case of his deviation in period 0 is:

$\pi_{M \kappa}^{D \mid M}=\left(1-\beta_{\kappa}\right) R\left(h^{*}, m^{D}\right)-m^{D}-f_{M}-T^{R}=\left[\left(1-\beta_{\kappa}\right)^{\frac{1}{1-\alpha(1-\eta)}}(1-\alpha(1-\eta))\right] A E L \Theta X^{-\frac{\alpha}{1-\alpha}}-f_{M}-T^{R}$

The competitive bidding process on the part of suppliers that we described above implies that the transfer $T^{R}$ is chosen such that $M$ 's one-shot pure profits are driven to zero, $\pi_{M \kappa}^{D \mid M}=0$. When the relational contract is broken in $t=0$ the co-operation partners negotiate in all subsequent periods $t=1, \ldots, \infty$ on the spot and the supplier obtains zero profits $\pi_{M k}^{T B}=0$ (see (16)). Hence, pure profits of component suppliers on the entire deviation path are equal to zero.

Consider now $H$ 's pure profits on the deviation path supposing that $M$ sticks to the relational agreement and provides the first best investment $m^{*}$ in period $0 . H$ then solves $\max _{h_{\kappa}^{D}} \beta_{\kappa} R\left(h_{\kappa}^{D}, m^{*}\right)-h_{\kappa}^{D}-f_{H}+T^{R}$ s.t. $m^{*}=(1-\eta) \alpha A E L \Theta X^{-\frac{\alpha}{1-\alpha}}$, yielding the following oneshot investment and revenue:

$$
h_{\kappa}^{D}=\beta_{\kappa}^{\frac{1}{1-\alpha \eta}} \eta \alpha A E L \Theta X^{-\frac{\alpha}{1-\alpha}} \Rightarrow R\left(h_{\kappa}^{D}, m^{*}\right)=\beta_{\kappa}^{\frac{\alpha \eta}{1-\alpha \eta}} A E L \Theta X^{-\frac{\alpha}{1-\alpha}} .
$$

The one-shot pure profit of party $H$ is then:

\footnotetext{
${ }^{27}$ This results from the complementarity of investments and the fact that $H$ invests more than in the third-best case.
} 


$$
\begin{aligned}
\pi_{H \kappa}^{D \mid H} & =\beta_{\kappa} R\left(h_{\kappa}^{D}, m^{*}\right)-h_{\kappa}^{D}-f_{H}+T^{R}=\left[\beta_{\kappa}^{\frac{1}{1-\alpha \eta}}(1-\alpha \eta)\right] A E L \Theta X^{-\frac{\alpha}{1-\alpha}}-f_{H}+T^{R} \\
& =A E L \Theta X^{-\frac{\alpha}{1-\alpha}}\left[\beta_{\kappa}^{\frac{1}{1-\alpha \eta}}(1-\alpha \eta)+\left(1-\beta_{\kappa}\right)^{\frac{1}{1-\alpha(1-\eta)}}(1-\alpha(1-\eta))\right]-f,
\end{aligned}
$$

where the last transformation uses $T^{R}$ from (29). In view of the fact that $\pi_{M k}^{T B}=0$ as a result of the transfer $T^{R}$, we can consolidate both parties' deviation profits and implement the redefinition $\pi_{\kappa}^{D} \equiv \pi_{H \kappa}^{D \mid H}$. The latter expresses that the one-shot pure deviation profit of $H$ comprises the joint one-shot pure deviation profit of the headquarter and the supplier. Hence, $\pi_{\kappa}^{D}$ expresses both parties' temptation to deviate.

The following Lemma establishes that if $M$ sticks to the relational contract (i.e., provides $m^{*}$ ), $H$ 's one shot pure profits from deviation are higher than his profits in the first-best case (see (9)).

Lemma 2. $\pi_{\kappa}^{D}>\pi^{*}$ for all $\alpha, \eta, \beta_{\kappa} \in(0,1)$.

\section{Proof. See Appendix E.}

Intuitively, by demanding the ex ante transfer $T^{R}$ and refusing to pay the ex post bonus $B, H$ can collect exorbitant profits. However, these profits can be reaped only in $t=0$. The spot game is then played in all subsequent periods implying headquarter's profits $\pi_{H k}^{T B}=\pi_{k}^{T B}<\pi^{*}$.

\subsection{Incentive compatibility constraint}

We now analyze the condition under which relational contracts emerge. Note first that by the construction of the transfer-bonus system, a component supplier is not worse off by providing the first-best investment $m^{*}$ than by defecting (i.e. by supplying $m_{\kappa}^{D}<m^{*}$ in period 0 ). The bonus is implicitly defined by $\pi_{M}^{*}\left(h^{*}, m^{*}\right)=B-m^{*}-f_{M}-T^{R}=0$. We assume that the supplier prefers cooperation to defection in case that both actions yield the same reward $\left(\pi_{M}^{*}\left(h^{*}, m^{*}\right)=\pi_{M \kappa}^{D \mid M}\left(h^{*}, m_{\kappa}^{D}\right)=0\right)$. If both parties behave cooperatively, the headquarter's pure profits are given by $\pi_{H}^{*}\left(h^{*}, m^{*}\right)=R\left(h^{*}, m^{*}\right)-h^{*}-f_{H}+T^{R}-B$. Using $B=m^{*}+f_{M}+T^{R}$, these profits reduce to the joint pure profits $\pi^{*}$ as in (9). Given the trigger strategy specified in Table 1 and bearing in mind that $\pi_{M}^{*}=\pi_{M k}^{D \mid M}=\pi_{M k}^{T B}=0$ and $\pi_{H k}^{T B}=\pi_{k}^{T B}$, a relational contract is selfenforcing iff the following incentive compatibility constraint (ICC) holds: 


$$
\text { ICC }: \quad \frac{\left(\pi^{*}-\pi_{k}^{T B}\right)}{r} \geq \pi_{\kappa}^{D}-\pi^{*}
$$

As long as this $I C C$ holds, there exists a bonus $B$ which induces the first-best investment of both parties in perpetuity under organizational form $\kappa$. Following Baker et al. (2002: 52), we can interpret the left-hand side of (32) as the present value of the net total surplus (i.e. the total surplus from continuing the relationship (i.e. $\pi^{*}$ ), less the best fallback if either party should renege (i.e. $\left.\max \left\{\pi_{S O}^{T B}, \pi_{S I}^{T B}\right\}\right)$. The right-hand side is the maximum reneging temptation $(M R T)$ under relational contract $\kappa$, i.e., the joint one-shot reneging incentives less joint profits under cooperation. Notice that both relational ownership forms $(R I, R O)$ can induce the same investments $\left(h^{*}, m^{*}\right)$ and deliver the headquarter the same surplus $\pi^{*}$, iff the ICC is satisfied in either case. We show in the following that the temptation to renege on a relational agreement differs under the two organizational forms, however.

\subsection{Make-or-buy decision in the relational game}

To ensure that the ICC (32) is fulfilled, the headquarter has to minimize the maximum reneging temptation $M R T$, i.e. the right hand side of (32). This is achieved by choosing the governance mode $\kappa \in\{R I, R O\}$ such that the associated $\beta_{\kappa} \in\{R I, R O\}$ yields the minimal joint deviation profit $\pi_{\kappa}^{D} \equiv \pi_{H \kappa}^{D \mid H}$ with $\pi_{H \kappa}^{D \mid H}$ as characterized in $(31) .{ }^{28}$ Define $\Pi_{R}(\eta) \equiv \Pi_{R I}^{D} / \Pi_{R O}^{D}$ to be the ratio of operating deviation profits under relational integration to those under relational outsourcing. Using (31) and focussing on the operating profits yields:

$$
\Pi_{R}(\eta) \equiv \frac{\Pi_{R I}^{D}}{\Pi_{R O}^{D}}=\frac{\left(1-\beta_{R I}\right)^{\frac{1}{1-\alpha(1-\eta)}}(1-\alpha(1-\eta))+\beta_{R I}^{\frac{1}{1-\alpha \eta}}(1-\alpha \eta)}{\left(1-\beta_{R O}\right)^{\frac{1}{1-\alpha(1-\eta)}}(1-\alpha(1-\eta))+\beta_{R O}^{\frac{1}{1-\alpha \eta}}(1-\alpha \eta)}
$$

Appendix $\mathrm{G}$ shows that $\Pi_{R}{ }^{\prime}(\eta)$ is a polynomial of degree 2 , hence the slope of $\Pi_{R}(\eta)$ is ambiguous. However, we prove analytically that if the headquarter intensity is low enough (e.g. for $\eta=0$ ) the reneging temptation is lower under relational outsourcing compared to relational integration (i.e. $\Pi_{R}(0)>1$ ), whereas if the headquarter intensity is high enough the converse holds (i.e. $\left.\Pi_{R}(1)<1\right)$. Furthermore, $\Pi_{R}{ }^{\prime}(\eta)<0$ around $\Pi_{R}(\eta)=1$. Hence we have:

\footnotetext{
${ }^{28}$ As in the spot game, if the headquarter could freely choose the revenue share in the bargain ex post, the $M R T$ would be always minimized and the choice of organizational form $\kappa=R I, R O$ would not matter. See appendix F.
} 
Proposition 3. Organizational choices under relational contracting. There exists a unique headquarter intensity $\hat{\eta}_{R} \in(0,1)$ such that in industries with $\eta<\hat{\eta}_{R}$ headquarters prefer relational outsourcing to relational integration (i.e. $\Pi_{R}(\eta)>1$ ), while in industries with $\eta>\hat{\eta}_{R}$ headquarters prefer relational integration to relational outsourcing (i.e. $\left.\Pi_{R}(\eta)<1\right)$. In industries with headquarter intensity $\eta=\hat{\eta}_{R}$ firms are indifferent between these two organizational forms.

Proof. See Appendix G.

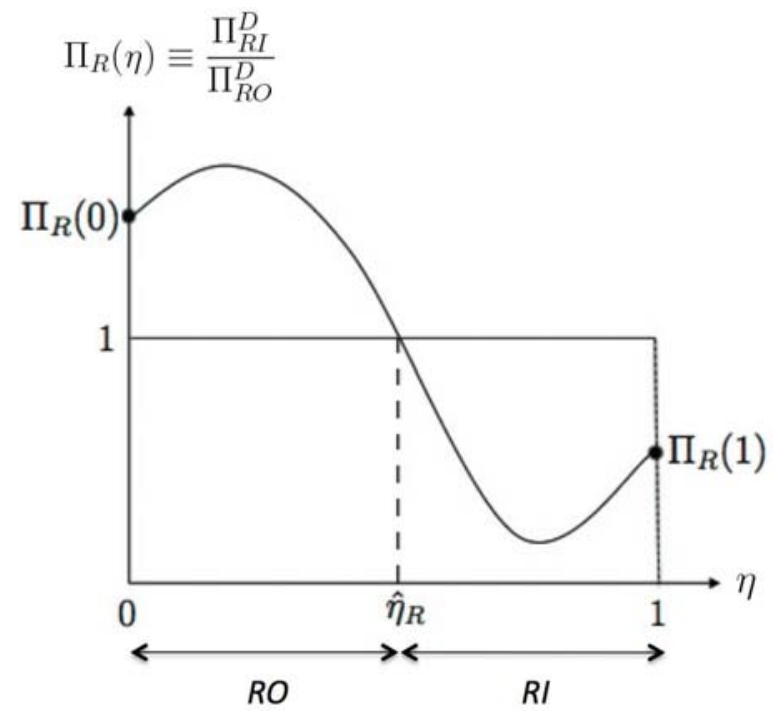

Figure 4: Organizational choice under relational contracting.

One possible run of $\Pi_{R}(\eta)$ is depicted in figure 4. Intuitively, $M$ 's investments in relational contracts are highest in industries with small headquarter intensity. Under these circumstances $H$ has the greatest incentive to cheat and reap a high one-shot deviation payoff. By leaving the property rights for components to the supplier (i.e. by strengthening the other party's bargaining position if the relational contract is broken), the headquarter minimizes his own incentives to renege and thereby signalizes his willingness to cooperate. Conversely, when $\eta$ gets larger, $M$ 's one-shot deviation incentives increase. For high enough headquarter intensity it becomes optimal to integrate the supplier into the firm boundaries to minimize the joint deviation incentives.

This section pursued the question whether relational integration or outsourcing minimizes the $M R T$ in the repeated game. However, the organizational form $\kappa$ that minimizes (31) does not necessarily render the $I C C$ self-enforcing. Through its left-hand side, the $I C C$ crucially depends 
on the firm-specific time preference rate $r$. The next section seeks the organizational form that ensures the first-best outcome for the greatest range of discount factors.

\subsection{Spot vs. relational contracting}

Using (9), (14) and (31) and bearing Lemma 2 in mind, the ICC (32) can be rearranged as: ${ }^{29}$

$$
\bar{r}=\frac{\pi^{*}-\pi_{k}^{T B}}{\pi_{\kappa}^{D}-\pi^{*}}=\frac{(1-\alpha)-\max _{k \in\{S O, S I\}}\left\{\beta_{k}^{\frac{\alpha \eta}{1-\alpha}}\left(1-\beta_{k}\right)^{\frac{\alpha(1-\eta)}{1-\alpha}}\left(1-\alpha\left[\beta_{k} \eta+\left(1-\beta_{k}\right)(1-\eta)\right]\right)\right\}}{\min _{\kappa \in\{R O, R I\}}\left\{\beta_{\kappa}^{\frac{1}{1-\alpha \eta}}(1-\alpha \eta)+\left(1-\beta_{\kappa}\right)^{\frac{1}{1-\alpha(1-\eta)}}(1-\alpha(1-\eta))\right\}-(1-\alpha)}
$$

where $\bar{r}$ denotes the cutoff rate of time preference which satisfies the ICC with equality. ${ }^{30}$ If $r<\bar{r}$ a headquarter can achieve the first-best outcome by means of relational contracting under organizational form $\kappa$. Otherwise, the parties negotiate in each period on the spot under organizational form $k$. The operators $\left.\max _{k}\{\}\right\}$ and $\min _{\kappa}\{\}$ denote the subgame perfect equilibria of the spot and relational game respectively.

Two important results are worth mentioning in view of (34). First, the feasibility of relational contracting does not depend on the firm-specific productivity $\theta$, but on the headquarter's time preference rate $r$. Hence, the long-term orientation of the headquarters affects their ability to conclude a relational agreement with suppliers and, thus, to achieve first-best rather than thirdbest profits. Therefore, in a given industry there may exist firms which differ in their profitability despite using the identical production technology $\theta$. Second, since the governance regime (be it spot or relational contracting) stipulated in period 0 is a subgame perfect equilibrium in each stage of the repeated game, the parties live forever under the regime agreed upon in the very first period. Consequently, differences in profitability between firms with different rates of time preference persist over time. It thus follows:

Proposition 4. Persistent performance differences between seemingly similar enterprises. Persistent performance differences between seemingly similar enterprises arise due to the heterogeneity of headquarters with respect to their rate of time preference.

\footnotetext{
${ }^{29}$ Notice, the aggregate consumption index $X$ is one of the variables that cancel out from the ICC. Intuitively, $X$ is exogenous from the viewpoint of a single firm and thus independent of its organizational structure.

${ }^{30}$ Since $\pi^{*}>\pi_{k}^{T B}$ (Lemma 1) and $\pi_{k}^{D}>\pi^{*}$ (Lemma 2), $\bar{r}$ is always positive. However, since the inequality $\pi_{\kappa}^{D}-\pi^{*}>\pi^{*}-\pi_{k}^{T B}$ is violated for some parameter values, the cutoff rate of time preference implied by (34) may as well lie above 1 . We return to this issue below.
} 
Proof. This follows immediately from equation (34) and our discussion above.

Numerical example. A firm's choice of the organizational mode is completely characterized by the parameters $\alpha, \eta, \beta_{k}, \beta_{\kappa} \in(0,1)$ and by the firm-specific rate of time preference $r$. In this section we provide an exemplary analysis of the make-or-buy decision for an industry with the following parameter values: $\beta_{S O}=\beta_{R O}=0.5, \beta_{S I}=\beta_{R I}=0.9$ and $\alpha=0.9$. Substituting these values into $\Pi_{S}(\eta)=1$ from (18) and solving for $\hat{\eta}_{S}$ yields the threshold headquarter intensity $\hat{\eta}_{S} \approx 0.75 .^{31}$ Hence, in industries with headquarter intensity $\eta<0.75$ firms choose spot outsourcing while in industries with $\eta>0.75$ spot integration is the chosen organizational form. Analogously, by substituting the parameter values into $\Pi_{R}(\eta)=1$ from (33), one numerically obtains the cutoff $\hat{\eta}_{R} \approx 0.67$. This threshold separates relational outsourcing and integration. Figure 5 depicts these cutoffs and the corresponding organizational modes. ${ }^{32}$

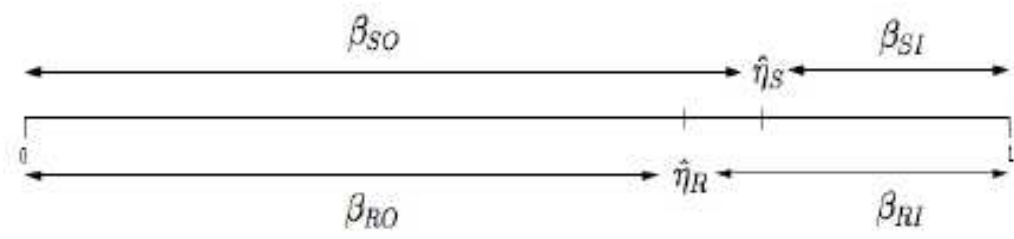

Figure 5: Cutoffs $\hat{\eta}_{S}$ and $\hat{\eta}_{R}$ for $\beta_{S O}=\beta_{R O}=1 / 2, \beta_{S I}=\beta_{R I}=0.9$ and $\alpha=0.9$.

Next, we can use this information in (34) to derive the cutoff rate of time preference $\bar{r}$ that pins down the choice between spot and relational governance. ${ }^{33}$ Numerical simulations are depicted in figure 6 by the curve that separates spot from relational contracting. For each headquarter intensity $\eta$ there exists a unique $\bar{r}$ such that headquarters with $r<\bar{r}$ conclude a relational agreement with suppliers, whereas firms with $r>\bar{r}$ operate under spot contracting. ${ }^{34}$

In the last step we derive the cutoff time preference rate $\tilde{r}$ for which the ex ante choice of the organizational mode in the relational contract is irrelevant, i.e. we seek $\tilde{r}$ such that firms with $r<\tilde{r}$ achieve the first-best outcome both under relational outsourcing and relational integration. Recall that for $\eta \in\left(0, \hat{\eta}_{R}\right)$ (for $\left.\eta \in\left(\hat{\eta}_{R}, 1\right)\right)$ relational outsourcing (relational integration) is the

\footnotetext{
${ }^{31}$ We performed these calculations in MAPLE. The worksheets are provided upon request.

${ }^{32}$ The ordering $\hat{\eta}_{R}<\hat{\eta}_{S}$ is not robust. If $\beta_{k}=\beta_{\kappa}$ is low enough the reverse ordering obtains.

${ }^{33}$ Remembering the results depicted in figure 5, we substitute for $\left\{\beta_{k}, \beta_{\kappa}\right\}$ the assumed values $\left\{\beta_{s o}, \beta_{R o}\right\}=\{0.5,0.5\}$ in the interval $\eta \in(0,0.67) ;\left\{\beta_{S o}, \beta_{R I}\right\}=\{0.5,0.9\}$ in the range $\eta \in(0.67,0.75)$, and $\left\{\beta_{S l}, \beta_{R l}\right\}=\{0.9,0.9\}$ in the range $\eta \in(0.75,1)$.

${ }^{34}$ Notice from figure 5 that some combinations of industry-specific parameter values may yield $\bar{r}>1$. In this case,
} 
dominant organizational form in the sense that it minimizes the MRT. The following thought experiment explores whether the ICC (34) still holds if a dominated instead of a dominant organizational form is chosen in a relational contract. ${ }^{35}$ In fact, as shown in figure 6 , there exists a range of time preferences rates (depicted by the area $R O \& R I$ ) which implies cooperative behavior independent of the ex ante choice of the organizational mode. Put differently, in a particular industry with headquarter intensity $\eta$ there exist multiple equilibria for the organizational mode of firms. ${ }^{36}$

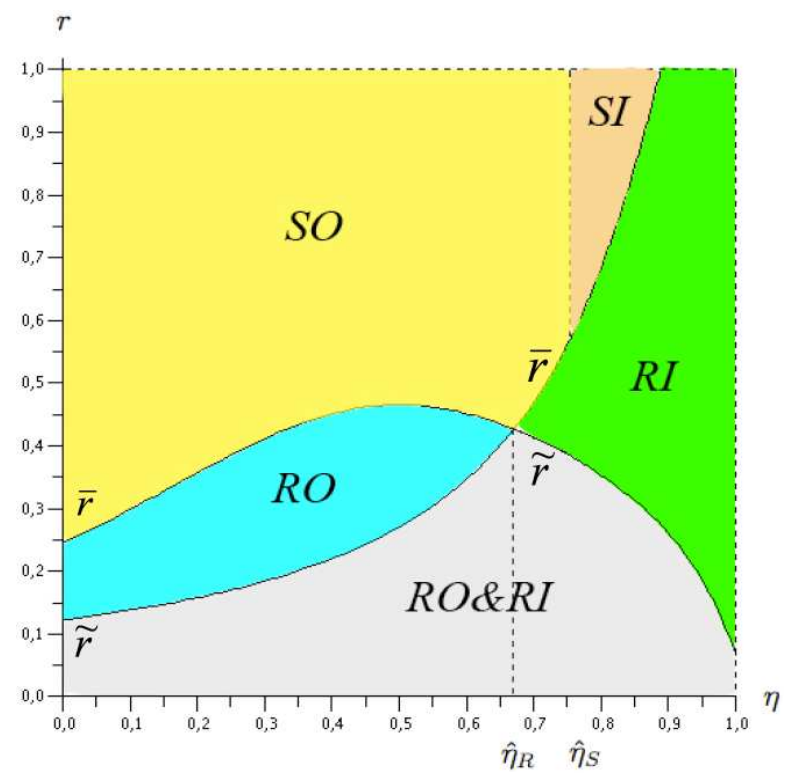

Figure 6: Dominant organizational forms for $\beta_{S O}=\beta_{R O}=1 / 2, \beta_{S I}=\beta_{R I}=0.9$ and $\alpha=0.9$.

Summing up the results of this section we have:

Proposition 5. Coexistence of organizational modes. Our model implies the coexistence of organizational modes in equilibrium. First, for a given headquarter intensity $\eta$ there do exist multiple equilibria in the sense that if the rate of time preference is low enough, both (relational) outsourcing and (relational) integration are viable. Second, if we allow the headquarter intensities to vary (say in a multi-industry version of our model), our model explains all four types of organizational modes.

Proof. This follows immediately from the discussion above.

all firms in the particual industry play relational contracting independently of firm-specific discount factors $r$.

35 More specifically, we utilize $\left\{\beta_{S O}, \beta_{R l}\right\}=\{0.5,0.9\}$ in the interval $\eta \in(0,0.67) ;\left\{\beta_{S o}, \beta_{R O}\right\}=\{0.5,0.5\}$ in the range $\eta \in(0.67,0.75)$, and $\left\{\beta_{S l}, \beta_{R o}\right\}=\{0.9,0.9\}$ in the range $\eta \in(0.75,1)$.

${ }^{36}$ For instance, given the parameters underlying figure 6, possible organizational forms existing in the industry with headquarter intensity $\eta=0.3$ are $S O, R O, R I$. 
The seminal analysis by Antràs and Helpman (2004) explains the coexistence of ownership modes on the industry level by assuming exogenous differences in fixed costs between different organizational forms. We drop this ad hoc assumption which, arguably, sits somewhat uncomfortably with the concept of a 'unified theory of the firm' envisioned by Grossman and Hart (1986) which seeks to derive both costs and benefits of organizational forms endogenously. Instead we provide an explanation for the coexistence of organizational modes which builds on the idea of relational contracting and in which the rate of time preferences plays a crucial role, thereby providing a further step towards such a 'unified theory'.

\subsection{Equilibrium in the repeated game}

Free entry condition. Let $v^{*}(r, \theta, X) \equiv \sum_{t=0}^{\infty}\left(\frac{1}{1+r}\right)^{t} \pi^{*}=\frac{(1+r)}{r} \pi^{*}$ denote the present value of the profit flow under relational contracting with $\pi^{*}$ as given in (9). These profits are achievable if the firm-specific time preference $r$ lies below the threshold $\bar{r}$ defined in (34). While the choice of the governance mode does not depend on $\theta$, a firm needs to be sufficiently productive in order to cover the fixed production cost to remain in the market. Hence, only such firms survive under relational contracting whose productivity level is above the cutoff $\theta^{*}$ implied by (20). Analogously, let $v_{k}^{T B}(r, \theta, X) \equiv \sum_{i=0}^{\infty}\left(\frac{1}{1+r}\right)^{t} \pi_{k}^{T B}=\frac{(1+r)}{r} \pi_{k}^{T B}$ represent the present value of the profit flow under spot contracting where $\pi_{k}^{T B}$ is given by (17). These profits can be obtained if $r>\bar{r}$ and they are positive if $\theta>\theta^{T B}$, where the threshold productivity in the third-best case is determined by (24). Free entry ensures that the expected pure profits of a potential headquarter equal the fixed cost of entry, $f_{E}$. Thus, the free entry condition in the repeated (rep) game can be expressed as:

$$
\int_{\varepsilon}^{\bar{r}} \int_{\theta^{*}}^{\infty} v^{*}\left(r, \theta, X^{r e p}\right) d G(\theta) d \Gamma(r)+\int_{\bar{r}}^{1} \int_{\theta^{T B}}^{\infty} v_{k}^{T B}\left(r, \theta, X^{r e p}\right) d G(\theta) d \Gamma(r)=f_{E} .
$$

General equilibrium. The general equilibrium in this repeated game is completely characterized by the zero cutoff profit conditions (ZCPC*) and $\left(\mathrm{ZCPC}^{T B}\right)$ given in (20) and (24), respectively, the incentive compatibility constraint (34) and the free entry condition (35). The equilibrium can be solved out analytically by assuming specific parameterizations of the distribution functions 
$G(\theta)$ and $\Gamma(r)$. While we maintain the assumption that the technology parameter is Paretodistributed, we assume that the rate of time preference can take on only two values, $r_{\text {low }}<\bar{r}$ and $r_{\text {high }}>\bar{r}$ with respective probabilities $\lambda$ and $(1-\lambda) .{ }^{37}$ Following the approach sketched in Appendix D, we can solve out (35) for the net present value of the aggregate consumption index:

$$
X^{r e p}(\lambda)=b\left(\frac{f}{f_{E}} \frac{\sigma-1}{(z-\sigma+1)}\right)^{\frac{1}{z}} \cdot\left(\frac{A E L}{f}\right)^{\frac{1-\alpha}{\alpha}} \cdot \Omega(\lambda)^{\frac{1}{z}}
$$

where $\Omega(\lambda) \equiv\left(\Lambda_{R} \cdot(1-\alpha)^{\frac{z(1-\alpha)}{\alpha}}+\Lambda_{S} \cdot \Psi_{k}^{\frac{z(1-\alpha)}{\alpha}}\right), \Lambda_{R} \equiv \lambda \cdot \frac{1+r_{\text {low }}}{r_{\text {low }}}, \Lambda_{S} \equiv(1-\lambda) \cdot \frac{1+r_{\text {low }}}{r_{\text {low }}}$

$\Omega(\lambda)$ can be interpreted as a measure of the efficiency of the economy in the face of contractual incompleteness. The following lemma can be established:

Lemma 3. $\Omega^{\prime}(\lambda)>0$.

Proof. Follows immediately from combining Lemma 1 with the fact that $r_{\text {low }}<r_{\text {high }}$.

Moreover, the higher is the share $\lambda$ of firms acting under relational governance, the less severe is the underinvestment on the firm level and the higher is the aggregate manufacturing output. The inspection of $X^{r e p}(\lambda)$ is particularly instructive for the two extreme cases $\lambda=1$ and $\lambda=0$. In the former case, (36) simplifies to $X^{\text {rep }}(1)=\left(\left(1+r_{\text {low }}\right) / r_{\text {low }}\right)^{1 / z} \cdot X^{*}$, where $X^{*}$ is the (per-period) first-best aggregate output from (22) and $\left(\left(1+r_{\text {low }}\right) / r_{\text {low }}\right)^{1 / z}$ denotes the effective discount factor. In the latter case, (36) simplifies to $X^{\text {rep }}(0)=\left(\left(1+r_{\text {high }}\right) / r_{\text {high }}\right)^{1 / z} \cdot X_{k}^{T B}$, where $X_{k}^{T B}$ is the thirdbest aggregate index given by (26). In the general case where $\lambda \in(0,1), X^{\text {rep }}(\lambda)$ is a convex combination of these extreme cases. Plugging (36) into (20) and (24) yields the equilibrium productivity cutoffs in the repeated game for firms engaged in relational and spot contracting, respectively,

$$
\theta_{R}^{r e p}(\lambda)=\theta^{*} \cdot(1-\alpha)^{-\frac{1-\alpha}{\alpha}} \cdot \Omega(\lambda)^{\frac{1}{z}} \quad, \quad \theta_{S}^{r e p}(\lambda)=\theta^{*} \cdot \Psi_{k}^{-\frac{1-\alpha}{\alpha}} \cdot \Omega(\lambda)^{\frac{1}{z}}
$$

where $\theta^{*}$ is given by (22). A comparison of both productivity cutoffs yields:

\footnotetext{
${ }^{37}$ The focus on two values of $r$ suffices for our purposes. However, the results can easily be replicated for general
} 
Proposition 6. Interaction of technology and organizational capabilities of the firms. In general equilibrium the minumum productivity cutoff $\theta_{S}^{\text {rep }}$ necessary for the survival of firms governed by spot contracting is higher than the minumum productivity cutoff $\theta_{R}^{\text {rep }}$ required for survival of firms governed by relational contracting.

Proof. This follows immediately from Lemma 1.

This proposition implies that short-sighted (spot) firms need to be more technologically versed than the more efficiently organized long-term oriented ones in order to be able to compete with the latter. As shown in Appendix H, we can express the average productivity in the repeated game as $\tilde{\theta}^{\text {rep }}(\lambda)=\left(\frac{z}{z-\sigma+1}\right)^{\frac{1-\alpha}{\alpha}} \cdot \theta^{*} \cdot \Omega(\lambda)^{\frac{1}{z}} \cdot K(\lambda)^{\frac{1-\alpha}{\alpha}}$, where $K(\lambda) \equiv\left(\frac{\lambda}{1-\alpha}+\frac{1-\lambda}{1-\alpha\left[\beta_{k} \eta+\left(1-\beta_{k}\right)(1-\eta)\right]}\right)$. It can be easily shown that $K^{\prime}(\lambda)>0$ for all $\alpha, \eta, \beta_{k} \in(0,1)$. Hence, by Lemma 3 , the average productivity in the repeated game, $\tilde{\theta}^{\text {rep }}(\lambda)$ is increasing in the share $\lambda$ of firms with low time preference rate. Consequently, the average price of monopolistic producers, $p\left(\tilde{\theta}^{\text {rep }}\right)=\left(\theta^{*} \alpha\right)^{-1} \cdot(z /(z-\sigma+1))^{-\frac{1-\alpha}{\alpha}} \cdot \Omega(\lambda)^{-\frac{1}{z}} \cdot K(\lambda)^{-\frac{1-\alpha}{\alpha}}$ is decreasing in $\lambda$. The price index in the repeated game, $P^{r e p}(\lambda)=\left(\theta^{*} \alpha\right)^{-1}(\mu L / f)^{-\frac{1-\alpha}{\alpha}} \cdot \Omega(\lambda)^{-\frac{1}{z}}$ is lower when $\lambda$ is higher. The equilibrium mass of firms, $\quad N^{r e p}(\lambda)=\left[P^{r e p}(\lambda) / p\left(\tilde{\theta}^{\text {rep }}\right)\right]^{-\frac{\alpha}{1-\alpha}}=[(z-\sigma+1) /(f z)] \cdot \mu L \cdot K(\lambda)^{-1}$ decreases in the share of headquarters with time preference rate $r_{l o w}<\bar{r}$. The expression for welfare

$$
V^{r e p}(\lambda)=1-\mu \ln P^{r e p}(\lambda)+\mu(\ln \mu-1)
$$

finalizes the characterization of the equilibrium in the repeated game.

\subsection{Country differences with respect to the distribution of the time preference rate}

We now turn to country differences with respect to the distribution of the time preference rate. We obtain:

Proposition 7. Country differences with respect to the distribution of the time preference

distributions of $r$. We provide the solution where both $G(\theta)$ and $\Gamma(r)$ are Pareto-distributed on request. 
rate. Suppose country 1 has a higher share of firms (headquarters) with low time preference, as compared to country 2, i.e. $\lambda_{1}>\lambda_{2}$. Then country 1 exhibits a higher aggregate consumption index $X^{\text {rep }}$, a lower price level $P^{\text {rep }}$ and higher welfare $V^{\text {rep }}$ than country 2.

Proof. Follows immediately from Lemma 3.

Intuitively, with $\lambda_{1}>\lambda_{2}$, compared to country 2 , country 1 has a higher share of long-term oriented headquarters (exhibiting a time preference rate $r_{\text {low }}<\bar{r}$ ) that enter a (first-best) efficient relational contract with suppliers. As a consequence, consumers in country 1 face a lower price level and have a higher welfare than consumers in country 2.

\section{$5 \quad$ Concluding comments}

This paper brings the notion of relational contracting, as formalized in a repeated game by Baker et al. (2002), into a tractable variant of the seminal models developed by Antràs (2003) and Antràs and Helpman (2004) to reconcile two empirical findings. First, the performance of firms is strongly affected by their capacity to solve organizational questions effectively and this capacity is apparently strongly related to their ability to maintain informal long-term relationships. Second, countries that are better at maintaining unwritten agreements and where interactions are more strongly guided by a sense of trust fare better in terms of economic welfare than others. Our micro-founded explanation shows how the trust that prevails in an economy gets transmitted into higher economic well-being and thereby highlights the role of managers with low time preference.

We also show that in our full general equilibrium model the basic make-or buy decision is similar under relational contracting as under spot contracting: if the headquarter intensity exceeds a certain threshold, headquarters prefer relational integration to relational outsourcing whereas the opposite holds below this threshold. Furthermore we show that: headquarters with low time preference are able to reap the fruits of relational contracts whereas those with high time preference are stuck with spot contracts, irrespective of their productivity status. Further, we are able to endogenously explain the coexistence of organizational modes - integration and outsourcing both in spot and relational firms. Hence, we also contribute a further step towards a 'unified theory of the firm' which seeks to derive both costs and benefits of organizational forms endogenously as envisioned by Grossman and Hart (1986). 


\section{References}

Acemoglu, D., P. Antràs, E. Helpman (2007): Contracts and Technology Adoption, American Economic Review, 97 (3), 916-943.

Arrow, K. (1972): Gifts and Exchanges, Philosophy and Public Affairs, 1, 343-362.

Algan, Y., P. Cahuc (2010): Inherited Trust and Growth, American Economic Review, forthcoming.

Antràs, P. (2003): Firms, Contracts and Trade Structure, Quarterly Journal of Economics, 118(4), 1375-1418.

Antràs, P., E. Helpman (2004): Global Sourcing, Journal of Political Economy, 112, 552-580.

Antràs, P., E. Helpman (2008): Contractual Frictions and Global Sourcing. In Helpman, E., D. Marin, T. Verdier (eds.) The Organization of Firms in a Global Economy, Harvard University Press.

Antràs, P., E. Rossi-Hansberg (2009): Organizations and Trade, Annual Review of Economics, 1, $43-64$.

Araujo, L. E. Ornelas (2007): Trust-Based Trade, mimeo.

Argote, L., S. Beckman, D. Epple (1990): The Persistence and Transfer of Learning in Industrial Settings, Management Science, 36(2), 140-154.

Baker, G., R. Gibbons, K. Murphy (2002): Relational Contracts and the Theory of the Firm, Quarterly Journal of Economics, 117(1), 39-84.

Beaulieu, N., R. Gibbons, R. Henderson (2010): Microeconometric Evidence of Persistent Performance Differences among Seemingly Similar Enterprises, MIT Working Paper. Forthcoming in Gibbons, R., J. Roberts (eds.): Handbook of Organizational Economics, Princeton University Press.

Bellemare, C., S. Kroeger (2007): On Representative Social Capital, European Economic Review, 51(1), 183202.

Bloom, N., J. Van Reenen (2007): Measuring and Explaining Management Practices Across Firms and Countries, Quarterly Journal of Economics, 122(4), 1341-1408.

Bloom, N., J. Van Reenen (2010): Why Do Management Practices Differ across Firms and Countries? Journal of Economic Perspectives, 24(1), 203-224.

Chew, W., T. Bresnahan, K. Clark (1990): Measurement, Coordination, and Learning in a Multiplant Network. In Kaplan, B. (ed.): Measures for Manufacturing Excellence, Boston: Harvard Business School Press.

Costinot, A. (2007): On the Origins of Comparative Advantage, Journal of International Economics, 77, 255264.

Dasgupta (1988): Trus as a Commodity. In Gambetta (ed): Trust: Making and Breaking Cooperative Relations, Cambridge, MA: Basil Blackwell.

Defever, F., F. Toubal (2007): Productivity and the sourcing modes of multinational firms: Evidence from French firm level data, CEP discussion paper, No 842.

Dincer, O., E. Uslaner (2010): Trust and Growth, Public Choice, 142, 59-67.

Dixit, A. (2004): Lawlessness and Economics - Alternative Models of Governance, Princeton: Princeton University Press.

Dixit, A., J. Stiglitz (1977): Monopolistic Competition and Optimum Product Diversity, American Economic Review, 67, 297-308.

Fehr, E., U. Fischbacher, B. von Rosenbladt, J. Schupp, G. Wagner (2003): A Nation-Wide Laboratory. Examining Trust and Trustworthiness by Integrating Behavioral Experiments into Representative Surveys, CESifo working paper 866.

Felli, L., J. Koennen, K. Stahl (2010): Trust and Investment - An Empirical Assessment, mimeo..

Frederick, S., G. Loewenstein, T. O’Donoghue (2002): Time Discounting and Time Preferences: A Critical Review, Journal of Economic Literature, 40, 351-401. 
Fukuyama, F. (1995): Trust: The Social Virtues and the Creation of Prosperity, NY: Free Press.

Galanter, M. (1981): Justice in Many Rooms: Courts, Private Orderings, and Indigenous Law, Journal of Legal Pluralism, 19, 1-47.

Gambetta, D. (1988): Can We Trust Trust? In Gambetta (ed): Trust: Making and Breaking Cooperative Relations, Cambridge, MA: Basil Blackwell.

Gibbons, R., R. Henderson, N. Repenning, and J. Sterman (2010): What Do Managers Do (To Build Competitive Advantage)? The Development of Relational Contracts and the Origins of Organizational Capability. Forthcoming in Gibbons, R., J. Roberts (eds.): Handbook of Organizational Economics, Princeton University Press.

Greif, A. (1993): Contract Enforceability and Economic Institutions in Early Trade: The Maghribi Traders' Coalition, American economic review, 83(3), 525-48.

Greif, A. (1994): Cultural Beliefs and the Organization of Society: A Historical and Theoretical Reflection on Collectivist and Individualist Societies, Journal of political economy, 102(5), 912-50.

Greif, A. (2006): Institutions and the Path to the Modern Economy: Lessons from Medieval Trade, Cambridge: Cambridge University Press.

Grossman, S., O. Hart (1986): The Costs and Benefits of Ownership: A Theory of Vertical and Lateral Integration, Journal of Political Economy, 94(4), 691-719.

Glaeser, E., D. Laibson, J. Scheinkman, C. Soutter (2000): Measuring Trust, Quarterly Journal of Economics, 115(3): 811-846.

Guiso, L., P. Sapienza, P, L. Zingales (2004): The Role of Social Capital in Financial Development, American Economic Review, 94, 526-556.

Guiso, L., P. Sapienza, P, L. Zingales (2006): Does Culture Affect Economic Outcomes? Journal of Economic Perspectives, 20, 23-48.

Guiso, L., P. Sapienza, P, L. Zingales (2009): Cultural Bias and Economic Exchange, Quarterly Journal of Economics, 124(3), 1095-1131.

Halonen, M. (2002): Reputation and the Allocation of Ownership, The Economic Journal, 112(481), 539-558.

Hart, O. (2002): Norms and the Theory of the Firm, University of Pennsylvania Law Review, 149(6), (June 2001), 1701-15. Reprinted in The Economics of Contracts, E. Brousseau and J.-M. Glachant, eds., Cambridge University Press.

Hart, O., J. Moore (1990): Property Rights and the Nature of the Firm, Journal of Political Economy, 98, 11191158.

Helpman, E. (2006): Trade, FDI, and the Organization of Firms, Journal of Economic Literature, 44(3), 589630.

Helpman, E., P. Krugman (1985): Market Structure and Foreign Trade, Cambridge, MA: MIT Press.

Helpman, E., M. Melitz, S. Yeaple (2004): Export versus FDI with Heterogenous Firms, American Economic Review, 94, 300-316.

Helpman, E., M. Melitz, Y. Rubinstein (2008): Estimating Trade Flows: Trading Partners and Trading Volumes, Quarterly Journal of Economics, 123, 441-487.

Henderson, R., I. Cockburn (1996): Scale, Scope, and Spillovers: The Determinants of Research Productivity in Drug Discovery, RAND Journal of Economics, 27(1), 32-59.

Ichniowski, C., K. Shaw, G. Prennushi (1997): The Effects of Human Resource Practices on Productivity: A Study of Steel Finishing Lines, American Economic Review, 87(3), 291-313.

James Jr., H. (2002): The Trust Paradox: A Survey of Economic Inquires Into the Nature of Trust and Trustworthiness, Journal of Economic Behaviour \& Organization, 47, 291-307.

Johnson, S., J. McMillan, C. Woodruff (2002): Courts and Relational Contracts, Journal of Law, Economics \& Organization, 18(1), 221-276. 
Kohler, W., M. Smolka (2009): Global Sourcing Decisions and Firm Productivity: Evidence from Spain, CESifo Working Paper, No. 2903.

Kortum, S. (1997): Research, Patenting, and Technological Change, Econometrica, 65, 1389-1419.

Knack, S., P. Keefer (1997): Does Social Capital Have an Economic Payoff? A Cross-Country Investigation, Quarterly Journal of Economics, 112(4), 1251-1288.

Kvaloy, O., T. Olsen (2009): Endogenous Verifiability and Relational Contracting, American Economic Review, 99(5), 2193-2208.

La Porta, R., F. Lopez-de-Silanes, A. Shleifer, R. Vishny (1997): Trust in Large Organizations, American Economic Review Papers and Proceedings, 87(2), 333-338.

Lawrance, E. (1991): Poverty and the Rate of Time Preference: Evidence from Panel Data, Journal of Political Economy, 99, 54-77.

Lazzarini, S., R. Madalozzo, R. Artes, J. Siqueira (2003): Measuring trust: An experiment in Brazil, Ibmec Working Paper No. 40.

Levchenko, A. (2007): Institutional Quality and International Trade, Review of Economic Studies, 74(3), 791819.

Macaulay, S. (1963): Non-Contractual Relationships in Business: A Preliminary Study, American Sociological Review, 28, 55-70.

MacLeod, B. (2007): Reputations, Relationships, and Contract Enforcement, Journal of Economic Literature, $45,595-628$.

Malcomson, J. (2010): Relational Incentive Contracts, Forthcoming in Gibbons R., J. Roberts (eds.): The Handbook of Organizational Economics. Princeton, NJ: Princeton University Press.

McMillan, J., C. Woodruff (1999): Interfirm Relationships and Informal Credit in Vietnam, Quarterly Journal of Economics, 114, 1285-1320.

Melitz, M. (2003): The Impact of Trade on Intraindustry Reallocations and Aggregate Industry Productivity, Econometrica, 71, 1695-1725.

Melitz, M., G. Ottaviano (2008): Market Size, Trade, and Productivity, Review of Economic Studies, 74, 295316.

Nunn, N. (2007): Relationship Specificity, Incomplete Contracts and the Pattern of Trade, Quarterly Journal of Economics, 122(2), 569-600.

Nunn, N., D. Trefler (2008): The Boundaries of the Multinational Firm: An Empirical Analysis. In Helpman, E., D. Marin, T. Verdier (eds.), The Organization of Firms in a Global Economy, Harvard University Press.

Putnam, R. (1993): Making Democracy Work: Civic Traditions in Modern Italy, Princeton NJ: Princeton University Press.

Samwick, S. (1998): Discount Rate Heterogeneity and Social Security Reform, Journal of Development Economics, 57, 117-146.

Sapienza, P., A. Toldra, L. Zingales (2008): Understanding Trust, mimeo.

Warner, J., S. Pleeter (2001): The Personal Discount Rate: Evidence from Military Downsizing Programs, American Economic Review, 91(1), 33-53.

Williamson, O. (1983): Credible Commitments: Using Hostages to Support Exchanges, American Economic Review, 73, 519-540. 


\section{Appendices}

\section{A Proof of Lemma 1}

Lemma $1\left(\Psi_{k}<(1-\alpha)\right)$ holds if and only if $\psi_{k} \equiv \Psi_{k}+\alpha<1$. Using (15), $\psi_{k}$ is given by

$$
\psi_{k}(\eta)=\beta_{k}^{\frac{\alpha \eta}{1-\alpha}}\left(1-\beta_{k}\right)^{\frac{\alpha(1-\eta)}{1-\alpha}}\left(1-\alpha\left[\beta_{k} \eta+\left(1-\beta_{k}\right)(1-\eta)\right]\right)+\alpha .
$$

By simple differentiation of this function with respect to $\eta$ it follows that $\psi^{\prime}(\eta) 0$ iff

$$
\gamma_{k} \ln \left(\frac{1-\beta_{k}}{\beta_{k}}\right) \leq(1-\alpha)\left(1-2 \beta_{k}\right)
$$

where $\gamma_{k} \equiv\left(1-\alpha\left(\beta_{k} \eta+\left(1-\beta_{k}\right)(1-\eta)\right)\right)>0$ for all $\alpha, \beta_{k}, \eta \in(0,1)$, and $\gamma^{\prime}(\eta\rangle 0$ if $\beta_{k} \leq 1 / 2$. The following properties result from the inspection of inequality (39):

(i) If $\beta_{k}<1 / 2$, then $\psi^{\prime}(\eta)<0, \forall \eta, \alpha \in[0,1]$.

(ii) If $\beta_{k}>1 / 2$, then $\psi^{\prime}(\eta)>0, \forall \eta, \alpha \in[0,1]$.

(iii) If $\beta_{k}=1 / 2$, then $\psi^{\prime}(\eta)=0, \forall \eta, \alpha \in[0,1]$.

Using these properties, the sufficient conditions for $\psi_{k}<1$ to hold simplify to $\psi(0)<1$ for $\beta_{k} \in(0,1 / 2) ; \psi(1)<1$ for $\beta_{k} \in(1 / 2,1)$, and $\psi(\eta)<1$ for $\beta_{k}=1 / 2$. It can be easily verified that these conditions hold for all $\alpha, \eta \in(0,1)$. This implies $\Psi_{k}<(1-\alpha)$.

\section{B Discussion of the second-best case in the spot game}

If a headquarter could freely choose his revenue share in the spot game, he would choose the second-best revenue share $\beta_{S}^{*}(\eta)$ which maximizes $(14):{ }^{38}$

$$
\beta_{S}^{*}(\eta)=\frac{\eta(\alpha \eta+1-\alpha)-\sqrt{\eta(1-\eta)(1-\alpha \eta)(\alpha \eta+1-\alpha)}}{2 \eta-1} .
$$

In order to show that $\beta_{S}^{*}$ is strictly increasing in $\eta$, we simplify the first derivative of (40) with respect to $\eta$ to get:

$$
\frac{\partial \beta_{s}^{*}}{\partial \eta}=\frac{(1-\alpha+2 \alpha \eta(1-\eta))\left[\frac{1}{2}-\alpha \eta(1-\eta)-\sqrt{\eta(1-\eta)(1-\alpha \eta)(\alpha \eta+1-\alpha)}\right]}{(1-2 \eta)^{2} \sqrt{\eta(1-\eta)(1-\alpha \eta)(\alpha \eta+1-\alpha)}} .
$$

$\beta_{S}^{* \prime}(\eta)>0$ holds if and only if $\Phi(\alpha) \equiv\left[\frac{1}{2}-\alpha \eta(1-\eta)-\sqrt{\eta(1-\eta)(1-\alpha \eta)(\alpha \eta+1-\alpha)}\right]>0$. The sign

\footnotetext{
${ }^{38}$ The second root of (14) is for all $\alpha, \eta \in(0,1)$ outside the assumed range of $\beta_{S}^{*} \in(0,1)$.
} 
of the first derivative of the latter function with respect to $\alpha$

$$
\Phi^{\prime}(\alpha)=\frac{\eta(1-\eta)\left[\frac{1}{2}-\alpha \eta(1-\eta)-\sqrt{\eta(1-\eta)(1-\alpha \eta)(\alpha \eta+1-\alpha)}\right]}{\sqrt{\eta(1-\eta)(1-\alpha \eta)(\alpha \eta+1-\alpha)}},
$$

is positive if and only if $\Phi(\alpha)>0$. Suppose this is not true and $\Phi(\alpha)<0$. If the latter is true, then it must be that $\Phi(1)<\Phi(0)$. However, it can be easily shown that $\Phi(1)>\Phi(0)>0$. This leads to a contradiction. It thus follows that $\Phi(\alpha)>0$ and, therefore, $\beta_{S}^{* \prime}(\eta)>0$.

Figure 7 plots $\beta_{S}^{*}(\eta)$ against $\eta$ for a given value of $\alpha$ (ignore all other information in this figure until further notice). The intuition behind a positive slope of $\beta_{S}^{*}(\eta)$ stems from the Property Rights Theory of the firm along the lines of Grossman and Hart (1986). The higher is the relative importance of headquarter services in production (i.e., the higher is $\eta$ ), the greater should be the headquarter's share of revenues in order to incentivize the ex ante investment of this party. More specifically, when headquarters get a share $\beta_{S}^{*}(\eta)$ of the ex post surplus, the joint underinvestment is minimized and, thus, (second-best) joint profits are maximized.

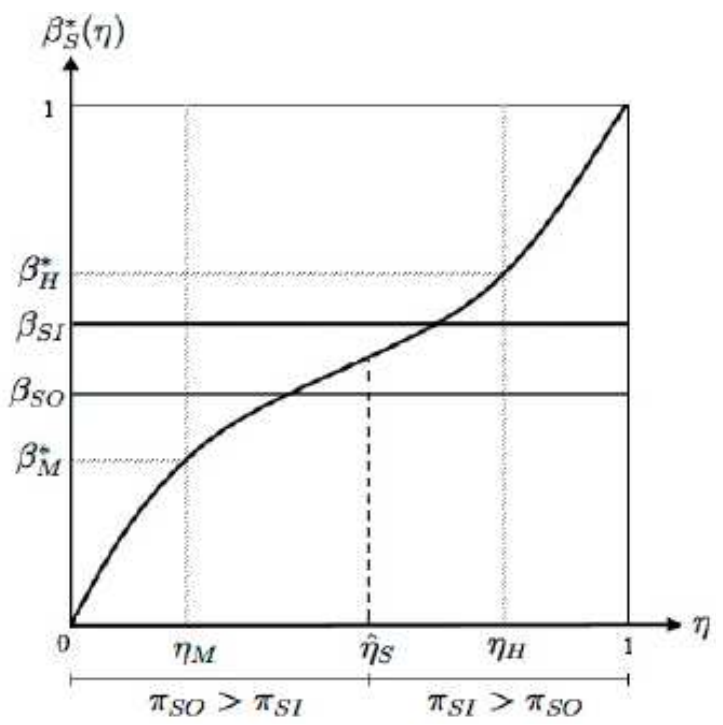

Figure 7: Bargaining shares and headquarter intensity

However, as mentioned in the main text, we assume that the contracting parties can not freely choose their revenue shares at the negotiation stage. Since bargaining weights and outside options are determined exogenously on the industry level, both parties' revenue shares are exogenous as well. For simplicity it is assumed that headquarters' shares of revenue, $\beta_{k}$ are independent of the headquarter intensity of the industry. These are indicated as straight lines $\beta_{S I}$ and $\beta_{S O}$ in figure 
7. By ex-ante choosing the organizational form $k=S I, S O$, the headquarter implicitly chooses a third-best bargaining share $\beta_{k}$ which comes closest to the second-best share derived in (40).

\section{Proof of Proposition 1}

In the first step of the proof we analyze the corner solutions of $\Pi_{S}(\eta)$. Using equation (18), we can establish

$$
\Pi_{S}(0)=\frac{1-\alpha\left(1-\beta_{S I}\right)}{1-\alpha\left(1-\beta_{S O}\right)}\left(\frac{1-\beta_{S I}}{1-\beta_{S O}}\right)^{\frac{\alpha}{1-\alpha}}<1 \quad \text { and } \quad \Pi_{S}(1)=\frac{1-\alpha \beta_{S I}}{1-\alpha \beta_{S O}}\left(\frac{\beta_{S I}}{\beta_{S O}}\right)^{\frac{\alpha}{1-\alpha}}>1 .
$$

The first inequality follows from $\beta_{S I}>\beta_{S O}$ and the fact that $(1-\alpha(1-x))(1-x)^{\alpha /(1-\alpha)}$ is a decreasing function of $x$ for all $x \in(0,1)$ and $\alpha \in(0,1)$. Analogously, the second inequality follows from the fact that $(1-\alpha x) x^{\alpha /(1-\alpha)}$ is an increasing function.

In the second step of the proof we consider the slope of the function $\Pi_{S}(\eta)$. From simple differentiation of (18), it follows that $\Pi_{S}^{\prime}(\eta)>0$ if and only if

$$
\Omega(\eta)\left(\ln \left(\frac{\beta_{S I}}{\beta_{S O}}\right)-\ln \left(\frac{1-\beta_{S I}}{1-\beta_{S O}}\right)\right)>\left(\beta_{S I}-\beta_{S O}\right)(2-\alpha)(1-\alpha),
$$

where $\quad \Omega(\eta) \equiv\left(1-\alpha\left(1-\beta_{S I}\right)+\alpha \eta\left(1-2 \beta_{S I}\right)\right)\left(1-\alpha\left(1-\beta_{S O}\right)+\alpha \eta\left(1-2 \beta_{S O}\right)\right) . \quad$ The following properties of the function $\Omega(\eta)$ can be proven analytically

(i) If $\beta_{S I}>\beta_{S O} \geq 1 / 2$, then $\Omega^{\prime}(\eta)<0, \forall \eta \in[0,1]$.

(ii) If $1 / 2<\beta_{S O}<\beta_{S I}$, then $\Omega^{\prime}(\eta)>0, \forall \eta \in[0,1]$.

(iii) If $\beta_{S I}>1 / 2>\beta_{S O}$, the algebraic sign of $\Omega^{\prime}(\eta)$ is ambiguous. However, in this case $\Omega^{\prime \prime}(\eta)<0, \forall \eta \in[0,1]$.

These properties imply that $\Omega(\eta) \geq \min \{\Omega(0), \Omega(1)\}, \forall \beta_{k}, \alpha, \eta \in(0,1)$. Without loss of generality, assume that $\Omega(1)=\left(1-\alpha \beta_{S I}\right)\left(1-\alpha \beta_{S O}\right)<\Omega(0) .{ }^{39}$ Therefore, if inequality (41) holds for $\Omega(1)$, it holds a fortiori for $\Omega(\eta), \forall \eta \in(0,1)$. Utilizing $\Omega(1)$ in (41) yields a sufficient condition for $\Pi_{S}^{\prime}(\eta)>0$ :

\footnotetext{
${ }^{39}$ The case $\Omega(1)>\Omega(0)$ is symmetric and can be proven by analogy.
} 


$$
\vartheta\left(\beta_{S I}\right) \equiv \ln \left(\frac{\beta_{S I}}{\beta_{S O}}\right)-\ln \left(\frac{1-\beta_{S I}}{1-\beta_{S O}}\right)-\frac{\left(\beta_{S I}-\beta_{S O}\right)(2-\alpha)(1-\alpha)}{\left(1-\alpha \beta_{S I}\right)\left(1-\alpha \beta_{S O}\right)}>0 .
$$

It can be seen immediately, that $\vartheta(\cdot)=0$ if $\beta_{S I}=\beta_{S O}$. Furthermore, from simple differentiation of $\vartheta\left(\beta_{S I}\right)$ it follows that $\vartheta^{\prime}\left(\beta_{S I}\right)>0$ if and only if $\left(1-\alpha \beta_{S I}\right)^{2}-\beta_{S I}(2-\alpha)(1-\alpha)\left(1-\beta_{S I}\right)>0$. It can be easily shown that this condition holds for all $\alpha, \beta_{S I} \in(0,1)$. Therefore, $\beta_{S I}>\beta_{S O}$ implies $\vartheta\left(\beta_{S I}\right)>0$ and thus $\Pi_{S}^{\prime}(\eta)>0$.

Combining the results concerning the corner solutions of $\Pi_{S}(\eta)$ and its slope, it follows that there exists a unique $\hat{\eta}_{S} \in(0,1)$ such that $\Pi_{S}(\eta)<1$ for all $\eta \in\left(0, \hat{\eta}_{S}\right), \Pi_{S}(\eta)>1$ for all $\eta \in\left(\hat{\eta}_{S}, 1\right)$ and $\Pi_{S}(\eta)=1$ for $\eta=\hat{\eta}_{S}$. The function $\Pi_{S}(\eta)$ from (18) is depicted in figure 2.

This results can also be interpreted in terms of figure 7 from Appendix B. Consider first an industry with low headquarter intensity (high manufacturing components intensity), $\eta_{M}$. In this case, the second best outcome could be achieved if headquarters got a share $\beta_{M}^{*}$ of the revenue. However, the actual bargaining shares are given by $\beta_{S I}$ and $\beta_{S O}$. Hence, by outsourcing the manufacturing production, the headquarter maximizes his profits. Consider next an industry with high headquarter intensity, $\eta_{H}$. Now, the second best would be achieved if $H$ got a share $\beta_{H}^{*}$ of the revenue. Given the industrial structure, the headquarter integrates a supplier into the production process in order to raise the highest profits. Proposition 1 implies the existence and uniqueness of cutoff $\hat{\eta}_{S}$ (between the lines $\beta_{S I}$ and $\beta_{S O}$ ) such that headquarters are indifferent between spot integration and spot outsourcing.

\section{Free entry condition and average productivity in the one-shot game}

We consider here only the first-best case, as corresponding conditions in the third-best case can be derived analogously. The free entry condition is set up along the lines of Helpman et al. (2004). Taking into account that both in the first-best profits (9) and the third-best profits (14), the productivity measure $\theta$ shows up with a common constant component $\alpha /(1-\alpha)$, captured in $\Theta \equiv \theta^{\alpha /(1-\alpha)}$, it proves convenient to define the distribution of firm sales as

$$
\Lambda(\theta) \equiv \int_{0}^{\theta} y^{\alpha(1-\alpha)} d G(y) \Rightarrow \Lambda(\theta)=c \cdot \theta^{\frac{z(\alpha-1)+\alpha}{1-\alpha}}=c \cdot \theta^{-z+(\sigma-1)}
$$


where $c \equiv \frac{z b^{z}(1-\alpha)}{z(\alpha-1)+\alpha}=\frac{z b^{z}}{\sigma-z-1}$ is a constant. ${ }^{40}$ The transformation in (42) was obtained by utilizing the probability density function from (19) and integrating the resulting expression. Using (9), expected pure profits of a potential headquarter in the first-best case simplify to

$$
\begin{aligned}
& \int_{\theta^{*}}^{\infty}\left((1-\alpha) A E L \theta^{\frac{\alpha}{1-\alpha}} X^{-\frac{\alpha}{1-\alpha}}-f\right) d G(\theta)=(1-\alpha) A E L X^{-\frac{\alpha}{1-\alpha}} \int_{\theta^{*}}^{\infty} \theta^{\frac{\alpha}{1-\alpha}} d G(\theta)-f \int_{\theta^{*}}^{\infty} d G(\theta)= \\
& (1-\alpha) A E L \theta^{\frac{\alpha}{1-\alpha}} X^{-\frac{\alpha}{1-\alpha}}\left[\Lambda(\infty)-\Lambda\left(\theta^{*}\right)\right]-f\left[1-G\left(\theta^{*}\right)\right],
\end{aligned}
$$

where $G\left(\theta^{*}\right), \theta^{*}$ and $\Lambda\left(\theta^{*}\right)$ are given by (19), (22) and (42), respectively. Since $\Lambda(\infty)=0$ (due to assumption $z>\sigma-1$ ), the free entry condition from (21) simplifies to

$$
(1-\alpha) A E L \theta^{\frac{\alpha}{1-\alpha}} X^{-\frac{\alpha}{1-\alpha}}\left[-\Lambda\left(\theta^{*}\right)\right]-f\left[1-G\left(\theta^{*}\right)\right]=f_{E} .
$$

Solving this equation for $X$ yields an expression for aggregate consumption index in (22). This index can be utilized in (20) to obtain the cutoff productivity in the first best case.

As is well-known from Melitz (2003), the CES price index (2) can be rewritten as $P^{*}=N^{1 /(1-\sigma)} \cdot p\left(\tilde{\theta}^{*}\right)=N^{1 /(1-\sigma)} \cdot \frac{1}{\alpha \tilde{\theta}^{*}}$, where $\tilde{\theta}^{*}$ is the average productivity which is defined as follows:

$$
\tilde{\theta}^{*} \equiv\left[\int_{0}^{\infty} \theta^{\frac{\alpha}{1-\alpha}} \xi(\theta) d \theta\right]^{\frac{1-\alpha}{\alpha}}=\left[\int_{0}^{\infty} \theta^{\sigma-1} \xi(\theta) d \theta\right]^{\frac{1}{\sigma-1}}, \quad \xi(\theta) \equiv\left\{\begin{array}{cl}
\frac{g(\theta)}{1-G\left(\theta^{*}\right)} & \text { if } \theta \geq \theta^{*} \\
0 & \text { otherwise }
\end{array}\right.
$$

$\xi(\theta)$ is the conditional distribution of $g(\theta)$ on $\left[\theta^{*}, \infty\right]$ and $1-G\left(\theta^{*}\right)$ is the ex-ante probability of successful entry. Using the definition of Pareto productivity from (19), the average productivity can be rearranged as follows: ${ }^{41}$

$$
\tilde{\theta}^{*}=\left[\frac{1}{1-G\left(\theta^{*}\right)} \int_{\theta^{*}}^{\infty} \theta^{\sigma-1} g(\theta) d \theta\right]^{\frac{1}{\sigma-1}}=\left[z\left(\theta^{*}\right)^{z} \int_{\theta^{*}}^{\infty} \theta^{\sigma-z-2} d \theta\right]^{\frac{1}{\sigma-1}}=\left[z\left(\theta^{*}\right)^{z} \frac{\left(\theta^{*}\right)^{\sigma-z-1}}{z-\sigma+1}\right]^{\frac{1}{\sigma-1}}=\theta^{*}\left[\frac{z}{z-\sigma+1}\right]^{\frac{1}{\sigma-1}} .
$$

\section{E Proof of Lemma 2}

Lemma $2\left(\pi_{\kappa}^{D} \equiv \pi_{H \kappa}^{D \mid H}>\pi^{*}\right)$ holds if and only if (cf. (31) and (9)):

\footnotetext{
${ }^{40}$ Pareto-distributed variable has a well-defined (finite) variance if and only if $z>2$. To ensure that variance of the distribution of firm sales is finite and integral converges (i.e., $\Lambda(\infty)=0$ ), we need to impose additionally $z>\sigma-1$, where $\sigma>1$ is the elasticity of substitution.
} 


$$
\operatorname{LHS}(\alpha) \equiv(1-\beta)^{\frac{1}{1-\alpha(1-\eta)}}(1-\alpha(1-\eta))+\beta^{\frac{1}{1-\alpha \eta}}(1-\alpha \eta)>(1-\alpha) \equiv \operatorname{RHS}(\alpha)
$$

In the first step of the proof we consider the corner solutions of both sides. We can establish:

$$
\operatorname{LHS}(0)=\operatorname{RHS}(0)=1, \quad \operatorname{LHS}(1)=(1-\beta)^{\frac{1}{1-\eta}} \eta+\beta^{\frac{1}{1-\eta}}(1-\eta)>0=\operatorname{RHS}(1)
$$

Next, consider the slopes of $\operatorname{LHS}(\alpha)$ and $R H S(\alpha)$. The first order derivative of $R H S$ with respect to $\alpha$ is a constant: $\operatorname{RHS}^{\prime}(\alpha)=-1$. Bearing in mind the corner solutions from above, the sufficient condition for $\operatorname{LHS}(\alpha)$ to lie above $R H S(\alpha)$ is $L H S^{\prime}(\alpha)>-1$. Taking the first order derivative of $L H S(\alpha)$ with respect to $\alpha$ and rearranging, this sufficient condition $S C$ can be expressed as:

$$
S C(\alpha)=(1-\beta)^{\frac{1}{1-\alpha(1-\eta)}}(1-\eta)\left(1-\frac{\ln (1-\beta)}{1-\alpha(1-\eta)}\right)+\beta^{\frac{1}{1-\alpha \eta}} \eta\left(1-\frac{\ln (\beta)}{1-\alpha \eta}\right)<1 .
$$

It can be shown that $S C^{\prime}(\alpha)>0$. Hence, if $S C(1)<1$ holds, $S C(\alpha)<1$ holds a fortiori for all $\alpha \in(0,1)$. In fact, it can be shown that $S C(1)<1$ for all $\beta, \eta \in(0,1)$. This implies $L H S(\alpha)>R H S(\alpha)$ and completes the proof of Lemma 2.

\section{F Discussion of the case in which $H$ could freely choose $\beta_{R}^{*}$ in the relational game}

If $H$ could freely choose his revenue share under relational contracting (i.e., if $\pi^{D}(\beta)$ from (31) were a continuous function of $\beta$ ), he would minimize (31) with respect to $\beta$ and would choose $\beta_{R}^{*}$ that solves the following implicit function:

$$
\left[\beta^{\frac{\alpha \eta}{1-\alpha \eta}}-(1-\beta)^{\frac{\alpha(1-\eta)}{1-\alpha(1-\eta)}}\right]=0
$$

The following properties of $\beta_{R}^{*}$ can be derived from the inspection of this function:

(i) For all $\alpha, \eta \in(0,1)$ there exists a unique $\beta_{R}^{*}$ which solves (44).

Proof. Note that (44) holds if and only if

$$
L H S(\beta) \equiv \frac{\ln \beta}{\ln (1-\beta)}=\frac{(1-\eta)(1-\alpha \eta)}{\eta(1-\alpha(1-\eta)} \equiv \operatorname{RHS}(\alpha, \eta)
$$

With regard to the left-hand side $L H S$ of the equation above we establish

${ }^{41}$ Again, we used the assumption $z>\sigma-1$ in the course of integration to assure that integrals converge. 


$$
\lim _{\beta \rightarrow 0} L H S(\beta)=\infty \quad, \quad \lim _{\beta \rightarrow 1} L H S(\beta)=0 \quad, \quad \frac{\partial L H S}{\partial \beta}=\frac{(1-\beta) \ln (1-\beta)+\beta \ln \beta}{(1-\beta) \beta(\ln (1-\beta))^{2}}<0 .
$$

As the range of the $R H S(\alpha, \eta)$ of equation above lies for all $\alpha, \eta \in(0,1)$ strictly between zero and infinity, there exists a single $\beta_{R}^{*}$ that fulfills equation (44).

(ii) $\beta_{R}^{*}$ is a global minimum of (31).

Proof. Taking the second derivative of (31) with respect to $\beta$ yields

$$
\frac{\partial^{2} \pi^{D}}{\partial \beta^{2}}=\frac{\alpha \eta}{1-\alpha \eta} \beta^{\frac{2 \alpha \eta-1}{1-\alpha \eta}}+\frac{\alpha(1-\eta)}{1-\alpha(1-\eta)} \beta^{\frac{2 \alpha(1-\eta)-1}{1-\alpha(1-\eta)}}>0 .
$$

As the second derivative is positive for all possible parameter values, $\beta_{R}^{*}$ is a local minimum of (31). Bearing in mind that the root of (44) is unique, see property $(i), \beta_{R}^{*}$ is simultaneously a global minimum of (31).

(iii) $\beta_{R}^{*}$ is increasing in $\eta$ for all $\alpha, \eta, \beta \in(0,1)$.

Proof. By implicitly differentiating (44), we get after simplification

$$
\frac{\partial \beta_{R}^{*}}{\partial \eta}=\frac{\beta(\beta-1)\left[\ln (1-\beta)(1-\alpha \eta)^{2}(1-\beta)^{\frac{\alpha(1-\eta)}{1-\alpha(1-\eta)}}+\ln \beta(1-\alpha(1-\eta))^{2} \beta^{\frac{\alpha \eta}{1-\alpha \eta}}\right]}{(1-\alpha \eta)(1-\alpha(1-\eta))\left(\beta(1-\eta)(1-\alpha \eta)(1-\beta)^{\frac{\alpha(1-\eta)}{1-\alpha(1-\eta)}}+(1-\beta) \eta(1-\alpha(1-\eta)) \beta^{\frac{\alpha \eta}{1-\alpha \eta}}\right.}>0 .
$$

As the negative term in the squared brackets is multiplied with another negative expression $(\beta(\beta-1)<0)$, the numerator of the above equation is positive.

Figure 8 plots the implicit function (44) for all possible values of $\alpha, \eta, \beta \in(0,1)$. It can be seen that for given values of $\alpha$ and $\eta$ there exists a unique bargaining share $\beta_{R}^{*}$ that solves (44). This is also illustrated in two-dimensional figure 9 for given values of $\alpha$.

Although both $\beta_{R}^{*}(\eta)$ from (44) and $\beta_{S}^{*}(\eta)$ from (40) have positive slope, the intuition behind these results is different. Recall that in the spot game the headquarter would optimally choose $\beta_{S}^{*}(\eta)$ in order to minimize joint underinvestment given by (12) and therefore to maximize joint profits from (14). In the relational game the headquarter would optimally choose $\beta_{R}^{*}(\eta)$ in order to minimize joint deviation incentives given by (31) and therefore to minimize the $M R T$ in (34). 


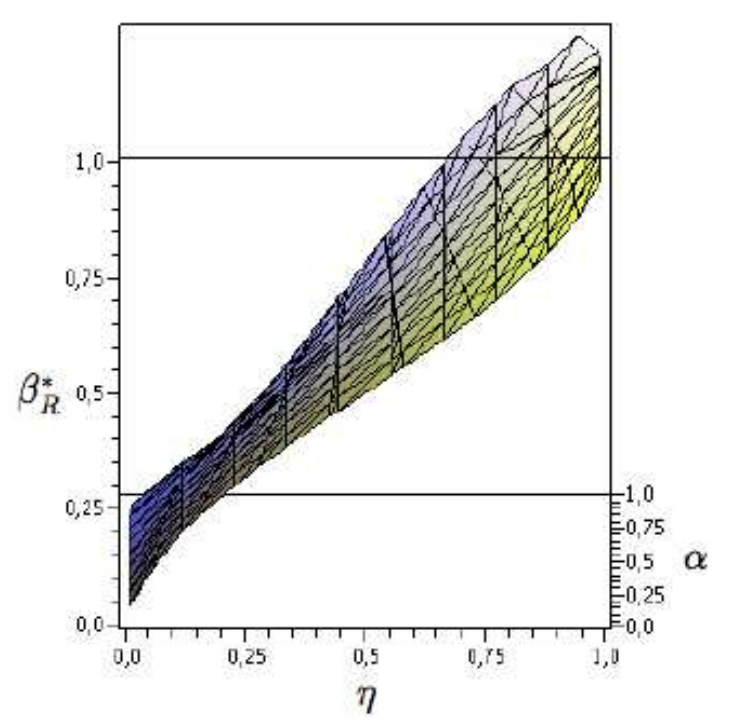

Figure 8: Implicit function (44) for $\alpha, \eta, \beta_{R}^{*} \in(0,1)$.

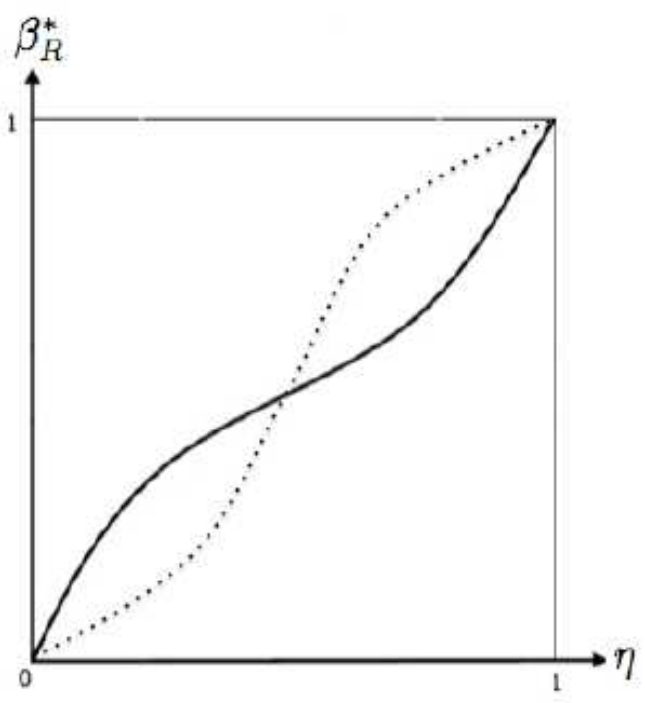

Figure 9: $\beta_{R}^{*}(\eta)$ for small (continuous function) and high (dotted function) $\alpha$.

\section{G Proof of Proposition 2}

In the first step of the proof we consider the corner solutions of $\Pi_{R}(\eta)$. From equation (33) we can establish

$$
\Pi_{R}(0)=\frac{\left(1-\beta_{R I}\right)^{\frac{1}{1-\alpha}}(1-\alpha)+\beta_{R I}}{\left(1-\beta_{R O}\right)^{\frac{1}{1-\alpha}}(1-\alpha)+\beta_{R O}}>1 \quad \text { and } \quad \Pi_{R}(1)=\frac{\left(1-\beta_{R I}\right)+\beta_{R I}^{\frac{1}{1-\alpha}}(1-\alpha)}{\left(1-\beta_{R O}\right)+\beta_{R O}^{\frac{1}{1-\alpha}}(1-\alpha)}<1 .
$$

The first inequality follows from $\beta_{R I}>\beta_{R O}$ and the fact that $(1-x)^{\frac{1}{1-\alpha}}(1-\alpha)+x$ is an increasing function of $x$ for all $x \in(0,1)$ and $\alpha \in(0,1)$. Analogously, the second inequality follows from the fact that $(1-x)+x^{\frac{1}{1-\alpha}}(1-\alpha)$ is a decreasing function.

In the second step of the proof we consider the slope of the function $\Pi_{R}(\eta)$. From simple differentiation of (33), it follows that $\Pi_{R}{ }^{\prime}(\eta)<0$ if and only if 


$$
\begin{array}{r}
-\frac{\left(1-\beta_{R I}\right)^{\frac{1}{1-\alpha(1-\eta)}} \alpha\left[1-\alpha(1-\eta)-\ln \left(1-\beta_{R I}\right)\right]}{1-\alpha(1-\eta)}-\frac{\beta_{R I}^{\frac{1}{1-\alpha \eta}} \alpha\left[1-\alpha \eta-\ln \beta_{R I}\right]}{1-\alpha \eta}< \\
\Pi_{R}(\eta) \cdot\left(\frac{\left(1-\beta_{R O}\right)^{\frac{1}{1-\alpha(1-\eta)}} \alpha\left[1-\alpha(1-\eta)-\ln \left(1-\beta_{R O}\right)\right]}{1-\alpha(1-\eta)}-\frac{\beta_{R O}^{\frac{1}{1-\alpha \eta}} \alpha\left[1-\alpha \eta-\ln \beta_{R O}\right]}{1-\alpha \eta}\right),
\end{array}
$$

whereas $\Pi_{R}(\eta)$ is given in equation (33). Since $[1-\alpha y-\ln x]>0$ holds for all $\alpha, y, x \in(0,1)$, all terms in squared brackets and therefore all fractions are positive. From this it follows that the lefthand side of inequality (45) is smaller than zero. While $\Pi_{R}(\eta)$ is strictly positive, the sign of the second term on the right-hand side is ambiguous. Numerical simulation have shown that above inequality does not hold for all parameter values. Hence, the sign of $\Pi_{R}{ }^{\prime}(\eta)$ is ambiguous.

Nevertheless, it can be proven analytically that (45) is fulfilled if evaluated at $\Pi_{R}(\eta)=1$. To show this, denote the first fraction on the left-hand side of inequality (45) as $T_{1}\left(\beta_{R I}\right)$ and the second fraction on the left-hand side of inequality (45) as $T_{2}\left(\beta_{R I}\right)$. Both functions are positive and their first derivatives are given by

$$
T_{1}{ }^{\prime}\left(\beta_{R I}\right)=\frac{\alpha\left(1-\beta_{R I}\right)^{\frac{\alpha(1-\eta)}{1-\alpha(1-\eta)}} \ln \left(1-\beta_{R I}\right)}{(1-\alpha(1-\eta))^{2}}<0 \quad, \quad T_{2}{ }^{\prime}\left(\beta_{R I}\right)=-\frac{\alpha \beta_{R I}^{\frac{\alpha \eta}{1-\alpha \eta}} \ln \beta_{R I}}{(1-\alpha \eta)^{2}}>0 .
$$

Therefore, if inequality (45) holds for $T_{1}(1)$, it holds a fortiori for all $\beta_{R I} \in(0,1)$. Analogously, if inequality (45) holds for $T_{2}\left(\beta_{R I}=\beta_{R O}\right)$, it holds a fortiori for all $\beta_{R I} \in\left(\beta_{R O}, 1\right)$. By substituting $\beta_{R I}=1$ and $\beta_{R I}=\beta_{R O}$ respectively in the first $\left(T_{1}\left(\beta_{R I}\right)\right)$ and second $\left(T_{2}\left(\beta_{R I}\right)\right)$ term of the lefthand side of inequality (45) and, by utilizing $\Pi_{R}(\eta)=1$ on the right-hand of (45), it simplifies to

$$
0<\frac{\left(1-\beta_{R O}\right)^{\frac{1}{1-\alpha(1-\eta)}} \alpha\left[1-\alpha(1-\eta)-\ln \left(1-\beta_{R O}\right)\right]}{1-\alpha(1-\eta)} .
$$

Since this inequality holds for all parameter values, the function $\Pi_{R}{ }^{\prime}(\eta)$ if evaluated at $\Pi_{R}(\eta)=1$ has a negative slope for all $\alpha, \eta, \beta_{\kappa} \in(0,1)$.

Next, it can be shown analytically that the polynomial $\Pi_{R}{ }^{\prime}(\eta)$ has degree $2 .^{42}$ Thus, the function $\Pi_{R}(\eta)$ has at most two extreme values. A possible run of the function $\Pi_{R}(\eta)$ is depicted in

\footnotetext{
${ }^{42}$ This can be seen from the highest exponent for $\eta$ in the numerator of the factorized equation $\Pi_{R}{ }^{\prime}(\eta)$. Elaborate calculations are available upon request.
} 
figure 4. Given our results concerning corner solutions, the slope and the degree of polynomial $\Pi_{R}(\eta)$, it thus follows that there exists a unique $\hat{\eta}_{R} \in(0,1)$ such that $\Pi_{R}(\eta)>1$ for all $\eta<\hat{\eta}_{R}$, $\Pi_{R}(\eta)<1$ for all $\eta>\hat{\eta}_{R}$, and $\Pi_{R}(\eta)=1$ for $\eta=\hat{\eta}_{R}$.

\section{$H$ Average productivity in the repeated game}

The CES price index in the repeated game is given by:

$$
P^{r e p}(\lambda)=\left[\int_{\theta_{R}^{r e p}}^{\infty}\left(p^{*}\right)^{1-\sigma} \cdot N^{r e p} \cdot \lambda \cdot \frac{g(\theta)}{1-G\left(\theta_{R}^{r e p}\right)} d \theta+\int_{\theta_{S}^{r e p}}^{\infty}\left(p_{k}\right)^{1-\sigma} \cdot N^{r e p} \cdot(1-\lambda) \cdot \frac{g(\theta)}{1-G\left(\theta_{S}^{r e p}\right)} d \theta\right]^{\frac{1}{1-\sigma}},
$$

where $p^{*}$ and $p_{k}$ are given by (8) and (13), respectively. As in Appendix D, we can rewrite this index as $P^{\text {rep }}(\lambda)=N^{1 /(1-\sigma)} \cdot p\left(\tilde{\theta}^{\text {rep }}\right)=N^{1 /(1-\sigma)} \cdot \frac{1}{\alpha \tilde{\theta}^{\text {rep }}}$, where $\tilde{\theta}^{\text {rep }}(\lambda)$ ist the average productivity defined as follows:

$$
\tilde{\theta}^{\text {rep }}(\lambda)=\left[\lambda \cdot \frac{1}{1-G\left(\theta_{R}^{\text {rep }}\right)} \int_{\theta_{R}^{\text {rep }}}^{\infty} \theta^{\sigma-1} g(\theta) d \theta+(1-\lambda) \cdot \frac{1}{1-G\left(\theta_{S}^{\text {rep }}\right)} \cdot\left(\left(\beta_{k}\right)^{\eta}\left(1-\beta_{k}\right)^{1-\eta}\right)^{\sigma-1} \cdot \int_{\theta_{S}^{\text {rep }}}^{\infty} \theta^{\sigma-1} g(\theta) d \theta\right]^{\frac{1}{\sigma-1}}
$$

Using the same approach as below equation (43), this term simplifies to:

$$
\tilde{\theta}^{\text {rep }}(\lambda)=\left[\left(\frac{z}{z-\sigma+1}\right) \cdot\left(\lambda \cdot\left(\theta_{R}^{\text {rep }}\right)^{\sigma-1}+(1-\lambda) \cdot\left(\left(\beta_{k}\right)^{\eta}\left(1-\beta_{k}\right)^{1-\eta}\right)^{\sigma-1} \cdot\left(\theta_{S}^{\text {rep }}\right)^{\sigma-1}\right)\right]^{\frac{1}{\sigma-1}} .
$$

Substituting for $\theta_{R}^{\text {rep }}$ and $\theta_{S}^{\text {rep }}$ respective terms from (37) and rearranging the resulting expression yields $\tilde{\theta}^{\text {rep }}(\lambda)=\left(\frac{z}{z-\sigma+1}\right)^{\frac{1}{\sigma-1}} \cdot \theta^{*} \cdot \Omega(\lambda)^{\frac{1}{z}} \cdot K(\lambda)^{\frac{1}{\sigma-1}}$, where $K(\lambda) \equiv\left(\frac{\lambda}{1-\alpha}+\frac{1-\lambda}{1-\alpha\left[\beta_{k} \eta+\left(1-\beta_{k}\right)(1-\eta)\right]}\right)$.

It can be easily shown that $K^{\prime}(\lambda)>0$ for all $\alpha, \eta, \beta_{k} \in(0,1)$. Hence, by Lemma 3 , the average productivity in the repeated game, $\tilde{\theta}^{r e p}(\lambda)$ is increasing in $\lambda$. Consequently, the average monopoly price $p\left(\tilde{\theta}^{\text {rep }}\right)=\frac{1}{\alpha \theta^{*}} \cdot\left(\frac{z}{z-\sigma+1}\right)^{-\frac{1-\alpha}{\alpha}} \cdot \Omega(\lambda)^{-\frac{1}{z}} \cdot K(\lambda)^{-\frac{1-\alpha}{\alpha}}$ is decreasing in $\lambda$. 